\title{
Mechanisms Involved in Systemic Nicotine-Induced Glutamatergic Synaptic Plasticity on Dopamine Neurons in the Ventral Tegmental Area
}

\author{
Ming Gao, ${ }^{1}$ Yu Jin, ${ }^{1}$ Kechun Yang, ${ }^{1}$ Die Zhang, ${ }^{1}$ Ronald J. Lukas, ${ }^{2}$ and Jie $\mathrm{Wu}^{1}$ \\ Divisions of ${ }^{1}$ Neurology and ${ }^{2}$ Neurobiology, Barrow Neurological Institute, St. Joseph's Hospital and Medical Center, Phoenix, Arizona 85013
}

\begin{abstract}
Systemic exposure to nicotine induces glutamatergic synaptic plasticity on dopamine (DA) neurons in the ventral tegmental area (VTA), but mechanisms are largely unknown. Here, we report that single, systemic exposure in rats to nicotine $(0.17 \mathrm{mg} / \mathrm{kg}$ free base) increases the ratio of DA neuronal currents mediated by AMPA relative to NMDA receptors (AMPA/NMDA ratio) assessed $24 \mathrm{~h}$ later, based on slice-patch recording. The AMPA/NMDA ratio increase is evident within $1 \mathrm{~h}$ and lasts for at least $72 \mathrm{~h}$ after nicotine exposure (and up to $8 \mathrm{~d}$ after repeated nicotine administration). This effect cannot be prevented by systemic injection of either $\alpha 7$-nAChR (nicotinic ACh receptor)-selective [methyllycaconitine (MLA)] or $\beta 2^{\star}$-nAChR-selective [mecamylamine (MEC)] antagonists but is prevented by coinjection of MLA and MEC. In either nAChR $\alpha 7$ or $\beta 2$ subunit knock-out mice, systemic exposure to nicotine still increases the AMPA/ NMDA ratio. Preinjection in rats of a NMDA receptor antagonist MK-801((+)-5-methyl-10,11-dihydro-5H-dibenzo[a,d]cyclohepten5,10-imine maleate), but neither DA receptor antagonists [SCH-23390 ( $R$-(+)-7-chloro-8-hydroxy-3-methyl-1-phenyl-2,3,4,5tetrahydro-1H-3-benzazepine) plus haloperidol] nor a calcineurin inhibitor (cyclosporine), prevents the nicotine-induced increase in AMPA/NMDA ratio. After systemic exposure to nicotine, glutamatergic (but not GABAergic) transmission onto rat VTA DA neuronal inputs is enhanced. Correspondingly, DA neuronal firing measured $24 \mathrm{~h}$ after nicotine exposure using extracellular single-unit recording in vivo is significantly faster, and there is conversion of silent to active DA neurons. Collectively, these findings demonstrate that systemic nicotine acting via either $\alpha 7$ - or $\beta 2^{\star}$-nAChRs increases presynaptic and postsynaptic glutamatergic function, and consequently initiates glutamatergic synaptic plasticity, which may be an important, early neuronal adaptation in nicotine reward and reinforcement.
\end{abstract}

\section{Introduction}

Nicotinic acetylcholine receptors (nAChRs) exist as a family of diverse subtypes each having a characteristic subunit composition (Sargent, 1993; Charpantier et al., 1998, 1999; Klink et al., 2001; Le Novère et al., 2002; Yang et al., 2009). Several nAChR radioligand-binding/functional subtypes are expressed in the ventral tegmental area (VTA), where they play critical roles in the mediation of nicotine reward and dependence; (Sargent, 1993; Charpantier et al., 1998, 1999; Klink et al., 2001; Le Novère et al., 2002; Yang et al., 2009).

Based on studies in vivo, different nAChR subtypes in the VTA seem to play specific roles in the mediation of nicotinic effects relevant to nicotine reward and self-administration, and also to nicotinic reinforcement of other biologically rewarding events

\footnotetext{
Received April 15, 2010; revised July 30, 2010; accepted Aug. 24, 2010.

Work toward this project was supported by the Barrow Neurological Foundation and by grants from the Arizona Biomedical Research Commission (Grants 0028 and 0057), the Institute for Mental Health Research, Philip Morris International through their External Research Program, and the National Institutes of Health (Grants R01 NS040417 and R01 DA015389). We thank Dr. Denis Lecavalier for reading and editing this manuscript, and Drs. Boris Gutkin and Michael Graupner for their useful comments. We also thank Dr. Marina Picciotto for kindly providing nAChR $\alpha 7$ and $\beta 2$ subunit knock-out mice.

Correspondence should be addressed to Dr. Jie Wu, Professor and Director of Neural Physiology Laboratory, Division of Neurology, Barrow Neurological Institute, St. Joseph's Hospital and Medical Center, 350 West Thomas Road, Phoenix, AZ 85013. E-mail: Jie.Wu@chw.edu.

DOI:10.1523/JNEUROSCI.1943-10.2010

Copyright $\odot 2010$ the authors $\quad 0270-6474 / 10 / 3013814-12 \$ 15.00 / 0$
}

(Corrigall and Coen, 1989; Clarke, 1991; Stolerman and Shoaib, 1991; Nestler, 1992; Dani and Heinemann, 1996). For example, within minutes of acute nicotine exposure in VTA slice preparations, there is an enhancement of glutamatergic transmission interpreted to occur via activation of presynaptic $\alpha 7$-nAChRs and postulated to involve desensitization of $\alpha 4 \beta 2$ nAChRs on GABAergic neurons (Mansvelder and McGehee, 2000; Mansvelder et al., 2002). This coordinated enhancement of glutamatergic excitation and elimination of GABAergic inhibition could contribute to an induction of glutamatergic synaptic long-term potentiation (LTP) in VTA dopamine (DA) neurons (Mansvelder et al., 2002). This may provide a mechanism by which systemic administration of nicotine induces long-lasting DA release from the VTA onto nucleus accumbens (NAc) neurons (Imperato and Di Chiara, 1986; Schilström et al., 1998). However, these concepts based on the previous studies using slice preparations have not been assessed in vivo, i.e., under conditions where systemic exposure to nicotine modulates DA neuronal activity and synaptic functions in an intact nervous system. In addition, it is unclear which nAChR subtypes mediate systemic nicotine-induced glutamatergic synaptic plasticity in VTA DA neurons.

A novel experimental approach has been developed to assess glutamatergic synaptic plasticity using midbrain slice preparations after systemic exposure to addictive drugs, by which Saal et al. (2003) first demonstrated that a single administration of nic- 
otine enhanced the AMPA/NMDA ratio (the ratio of VTA DA neuronal currents mediated by AMPA receptors relative to those mediated by NMDA receptors) measured $24 \mathrm{~h}$ later. We have expanded on that previous, seminal work to elucidate mechanisms involved in systemic nicotine-induced glutamatergic synaptic plasticity. Based on pharmacological and genetic approaches, we show that the increase in AMPA/NMDA ratios assessed in vitro in VTA DA neurons induced by systemic nicotine exposure in vivo involves actions on either $\alpha 7$ - or $\beta 2^{*}$-nAChRs. We also show that systemic exposure to nicotine enhances glutamatergic excitatory but not GABAergic inhibitory neurotransmission in the VTA. Furthermore, we have provided in vivo electrophysiological evidence that elevated DA neuronal firing is maintained $24 \mathrm{~h}$ after a single injection of nicotine.

\section{Materials and Methods}

\section{Slice preparation and drug administration protocol}

The protocol for preparation of VTA slices from rodents was approved by the Institutional Animal Care and Use Committee of the Barrow Neurological Institute and St. Joseph's Hospital and Medical Center.

Wistar rats or C57BL/2 mice [wild-type (WT) or nAChR $\alpha 7$ or $\beta 2$ subunit knock-out (KO) mice, $16-23 \mathrm{~d}$ old] were used. Slices from the VTA were prepared as previously described (Ungless et al., 2001; Liu et al., 2005). Briefly, animals were housed under standard conditions at $22-24^{\circ} \mathrm{C}, 50-60 \%$ humidity, and a $12 \mathrm{~h}$ light/dark cycle. All experiments were in compliance with the Guide for the Care and Use of Laboratory Animals. At different time points (i.e., $10 \mathrm{~min}, 1,24$, or $72 \mathrm{~h}$, or $5 \mathrm{~d}$ ) after systemic injection of nicotine, animals were anesthetized (isoflurane USP) and then killed by decapitation. Horizontal midbrain slices $(250 \mu \mathrm{m})$ containing the VTA were cut using a vibratome 1000 (Vibratome 1000 plus; Jed Pella Inc.). Slices were prepared in an ice-cold, glycerol-based, artificial CSF containing (in $\mathrm{mm}$ ): $2.5 \mathrm{KCl}, 1.2 \mathrm{NaH}_{2} \mathrm{PO}_{4}$, $1.2 \mathrm{MgCl}_{2}, 2.4 \mathrm{CaCl}_{2}, 26 \mathrm{NaHCO}_{3}$, and 11 glucose further supplemented with $250 \mathrm{~mm}$ glycerol (Ye et al., 2006). The slices were then incubated for at least $1 \mathrm{~h}$ in a preincubation chamber (Warner Instruments) at room temperature $\left(22-24^{\circ} \mathrm{C}\right)$ in conventional artificial CSF containing (in mm): $125 \mathrm{NaCl}, 3 \mathrm{KCl}, 2 \mathrm{CaCl}_{2}, 1 \mathrm{MgCl}_{2}, 1.25 \mathrm{NaH}_{2} \mathrm{PO}_{4}, 26 \mathrm{NaHCO}_{3}$ and 10 glucose continuously saturated with $95 \% \mathrm{O}_{2}$ and $5 \% \mathrm{CO}_{2}$.

For drug administration, animals were given intraperitoneal injections to achieve the indicated doses of nicotine bitartrate $(0.1,0.5$ or $1.5 \mathrm{mg} / \mathrm{kg}$, which are equivalent to $0.033,0.17$ and $0.5 \mathrm{mg} / \mathrm{kg}$ free-base nicotine), methyllycaconitine citrate (MLA, $5.0 \mathrm{mg} / \mathrm{kg}$ ), mecamylamine $\mathrm{HCl}$ (MEC, $3.0 \mathrm{mg} / \mathrm{kg}$ ), MK-801((+)-5-methyl-10,11-dihydro-5 $\mathrm{H}$ dibenzo $[a, d]$ cyclohepten-5,10-imine maleate) $(1.0 \mathrm{mg} / \mathrm{kg})$, cyclosporine $(15 \mathrm{mg} / \mathrm{kg})$ or SCH-23390 (R-(+)-7-chloro-8-hydroxy-3-methyl-1phenyl-2,3,4,5-tetrahydro-1 $\mathrm{H}$-3-benzazepine) $(1 \mathrm{mg} / \mathrm{kg})$ plus haloperidol $(2 \mathrm{mg} / \mathrm{kg})$. Drugs were dissolved in saline $(0.9 \% \mathrm{NaCl}), 10 \%$ DMSO in saline (haloperidol) (Shi et al., 2000, 2007), or olive oil (cyclosporine) (Addy et al., 2007). Control animals were similarly injected but with control, drug-free vehicles of the corresponding compositions and in the same volumes. Drugs used for antagonism studies typically were injected 10 min before nicotine administration (Walters et al., 2006; Zanetti et al., 2007) except that cyclosporine exposure occurred $90 \mathrm{~min}$ before nicotine injection (Addy et al., 2007). Other drug doses are comparable to those known to be clinically or experimentally effective (Shi et al., 2000, 2007). All drugs were obtained from Sigma.

\section{Electrophysiological recordings}

Patch-clamp recordings from VTA slices. To prepare for conventional whole-cell recording, glass microelectrodes (GC-1.5; Narishige) were fashioned on a two-stage vertical pipette puller (P-830; Narishige), and the resistance of the electrode was 3-5 $\mathrm{M} \Omega$ when filled with internal solution. Cells were visualized under infrared-DIC (differential interference contrast) microscopy, and electrodes were positioned using a micromanipulator. After a tight seal (resulting in electrode resistance $>2$ $\mathrm{G} \Omega$ ) was formed between the electrode tip and the cell surface, suction was briefly applied until a whole-cell patch-clamp recording configuration was achieved (access resistance lower than $20 \mathrm{M} \Omega$ ). Series resistance was automatically compensated using a patch-clamp amplifier (Multiclamp 700A, Molecular Devices). Data acquisition and analysis were performed using a digitizer (DigiData 1332A, Molecular Devices) and pClamp 9.1 analysis software (Molecular Devices). Signals were filtered at $2 \mathrm{kHz}$ and sampled at $10 \mathrm{kHz}$. All recordings were performed at $31 \pm$ $1{ }^{\circ} \mathrm{C}$. Putative DA neurons were identified based on their pharmacological and physiological properties. Specifically, VTA DA neurons show the presence of prominent hyperpolarization-induced currents $\left(I_{h}\right)$ and have firing rates that are increased in the presence of $\mu$-opioid receptor ligand, DAMGO ([D-Ala ${ }^{2}$, NMe-Phe ${ }^{4}$, Gly ${ }^{5}$-ol]-enkephalin) (Johnson and North, 1992; Margolis et al., 2003). In the present study, all neurons from which data were collected and reported here exhibited profound $I_{\mathrm{h}}$. After establishing the conventional whole-cell configuration, in some experiments, a florescent dye (biocytin $2 \mathrm{mg} / \mathrm{ml}$ ) was delivered into recorded neurons at the end of the recording session, and immunohistochemical staining with an anti-tyrosine hydroxylase antibody was performed (Sargent, 1993; Charpantier et al., 1998, 1999; Klink et al., 2001; Le Novère et al., 2002; Yang et al., 2009) post hoc to confirm DA neuronal phenotype (supplemental Fig. 1, available at www. jneurosci.org as supplemental material).

For measurements of glutamate receptor-mediated currents, DA neurons were voltage-clamped at $+40 \mathrm{mV}$. Picrotoxin (PTX, $100 \mu \mathrm{M}$ ) was added to the bath solution to block $\mathrm{GABA}_{\mathrm{A}}$-receptor-mediated inhibitory synaptic transmission. First, a stable baseline recording of total evoked EPSCs (evEPSCs) was obtained for 5 min. Currents were evoked using a bipolar tungsten stimulation electrode (World Precision Instruments) placed $\sim 150 \mu \mathrm{m}$ rostral to the recording electrode and a stimulation pulse of duration $40 \mu$ s and frequency of $0.1 \mathrm{~Hz}$. Then the NMDA receptor antagonist D-APV $(50 \mu \mathrm{M})$ was applied to the bath for $10 \mathrm{~min}$ to define AMPA receptor-mediated EPSCs. Digital subtraction of AMPA receptor-mediated EPSCs from total evEPSCs from the same neuron was used to define NMDA receptor-mediated EPSCs. The ratio of VTA DA neuronal currents mediated by glutamatergic AMPA receptors relative to current mediated by NMDA receptors (AMPA/NMDA ratio) is used as a measure of glutamatergic synaptic plasticity. Each current response is averaged from 15 repetitive stimuli at a frequency of $0.1 \mathrm{~Hz}$. For AMPA/ NMDA ratio experiments, the whole-cell recording pipette (3-4 M $\Omega$ ) was filled with a solution containing (in mM): $120 \mathrm{CsCH}_{3} \mathrm{SO}_{3}, 20 \mathrm{HEPES}$ 0.4 EGTA, $2.8 \mathrm{NaCl}, 5$ TEA-Cl, $2 \mathrm{MgCl}_{2}$, $2.5 \mathrm{MgATP}$ and $0.3 \mathrm{GTP}(\mathrm{pH}$ 7.2-7.4 with $\mathrm{CsOH}$ ).

For assessments of presynaptic glutamatergic contributions to nicotine-induced alterations of synaptic potential measured in rat VTA DA neurons, a paired-pulse protocol was executed as described previously (Pu et al., 2006) for two stimuli at an interpulse interval of $50 \mathrm{~ms}$ in the presence of picrotoxin $(100 \mu \mathrm{M})$ to block GABAergic transmission. These experiments were performed in current-clamp mode, and the resting membrane potential was adjusted to be $\sim-70 \mathrm{mV}$. The paired-pulse ratio (PPR) was defined as the amplitude of the second response, $\mathrm{P} 2$, to the amplitude of the first response, $\mathrm{P} 1$. The whole-cell recording pipette was filled with intracellular solution containing in mM: 140 potassium gluconate, $5 \mathrm{KCl}, 10 \mathrm{HEPES}, 0.2$ EGTA, $2 \mathrm{MgCl}_{2}$, $4 \mathrm{MgATP}, 0.3 \mathrm{Na}_{2} \mathrm{GTP}$ and $10 \mathrm{Na}_{2}$-phosphocreatine ( $\mathrm{pH} 7.3$ with $\mathrm{KOH}$ ). Series resistance (15-30 M $\Omega$ ) was monitored throughout the whole-cell recording, and data were discarded if the resistance changed by $>20 \%$. Only two slices were obtained from each animal, and one cell was examined from each slice.

For assessments of presynaptic GABAergic effects of nicotine exposure, the protocol used was as for studies of glutamatergic transmission except that picrotoxin was not present, the neuron was held at $-20 \mathrm{mV}$ for recordings done in voltage-clamp mode, and NBQX $(10 \mu \mathrm{M})$ and D-APV $(50 \mu \mathrm{M})$ were present to block glutamatergic transmission (Liu et al., 2005).

For assessments of miniature EPSCs (mEPSCs), voltage-clamp recordings were done at a holding potential of $-70 \mathrm{mV}$ in the presence of the $\mathrm{GABA}_{\mathrm{A}}$ receptor blocker picrotoxin $(100 \mu \mathrm{M}), \mathrm{D}-\mathrm{APV}(50 \mu \mathrm{M})$, and the voltage-gated $\mathrm{Na}^{+}$channel blocker tetrodotoxin (TTX, $1 \mu \mathrm{M}$ ). Miniature IPSCs were similarly recorded but in the presence of $10 \mu \mathrm{M}$ NBQX, $50 \mu \mathrm{M}$ D-APV and $1 \mu \mathrm{M}$ TTX.

For measuring current-voltage $(I-V)$ relationships for AMPA receptor-mediated responses, the concentrations of $\mathrm{CaCl}_{2}$ and $\mathrm{MgCl}_{2}$ in 
artificial CSF were adjusted to 4 and $2 \mathrm{~mm}$, respectively, to prevent polysynaptic responses upon stimulation in the presence of bicuculline $(20 \mu \mathrm{M})$. D-APV $(100 \mu \mathrm{M})$ was added in the external solution to block NMDA receptor-mediated currents. Intracellular recording solution containing $100 \mu \mathrm{M}$ spermine (in $90 \mathrm{~mm} \mathrm{CsMeSO}_{3} \mathrm{H}, 5 \mathrm{~mm} \mathrm{MgCl}_{2}, 8 \mathrm{~mm}$ $\mathrm{NaCl}, 10$ mM EGTA, 20 mM HEPES, 1 mM QX-314, $0.5 \mathrm{~mm} \mathrm{Na}_{3} \mathrm{GTP}$, and 2 mm MgATP, pH 7.3 with $\mathrm{CsOH}, 250-270$ mOsm) was used. For generating $I-V$ curves for rectification measurements, cells were held at -60 , $-40,-20,0,+20$ or $+40 \mathrm{mV}$. Inward rectification was calculated by dividing the absolute amplitude of average EPSC measured at $-60 \mathrm{mV}$ by that at $+40 \mathrm{mV}$.

Extracellular single-unit recordings in anesthetized rats. Extracellular single-unit recordings were performed in anesthetized rats as described previously (Gao et al., 2007; Zhang et al., 2008). Rats (16-23 d old) were anesthetized with chloral hydrate $(400 \mathrm{mg} / \mathrm{kg}$, i.p., with supplemental doses administered via a lateral tail vein) and mounted in a stereotaxic instrument. Animal body temperature was maintained at $37^{\circ} \mathrm{C}$ by using a heating pad throughout the experiment. The skull was exposed and the wound margins were infiltrated with a $0.3 \%$ solution of mepivacaine hydrochloride. A glass microelectrode (5-10 M 2 ) filled with $2 \mathrm{M} \mathrm{NaCl}$ containing $2 \%$ pontamine sky blue dye was lowered through a small burr hole drilled above the VTA (3.0 mm anterior to the lambda, $0.5-0.9 \mathrm{~mm}$ lateral to the midline, $6.5-8.5 \mathrm{~mm}$ ventral to the cortical surface). VTA DA neurons were identified and recorded as described previously (Bunney et al., 1973; Grace and Bunney, 1980, 1983; Gao et al., 2007) based on evidence for positive/negative action potentials of long duration (2-5 $\mathrm{ms}$ ), a firing rate of $1-10 \mathrm{~Hz}$ with a slow irregular or burst firing pattern, low pitch sound produced on an audio amplifier, and a duration of $\geq 1.1$ $\mathrm{ms}$ from the start of the action potential to the negative trough (Ungless et al., 2004). Multiple cells were recorded from each animal using the "cell per track" technique (Bunney and Grace, 1978; Chiodo and Bunney, 1983). Twelve electrode tracks were made in the VTA, each separated by $200 \mu \mathrm{m}$. Interspike intervals (ISI) and firing rates were collected on-line to a personal computer.

\section{Genotyping of $n A C h R \alpha 7$ and $\beta 2$ subunit knock-out mice}

Genomic DNA from mice newly born to heterozygotic, nAChR $\alpha 7$ or $\beta 2$ subunit knock-out parents was extracted from mouse tail tips using the QIAgen DNeasy Blood \& Tissue Kit following the manufacturer's protocol. PCR amplification of the nAChR $\beta 2$ subunit or lac-Z (an indicator for the knock-out) were performed using purified genomic DNA as the template and gene-specific primer pairs ( $\beta 2$ subunit forward primer: CGG AGC ATT TGA ACT CTG AGC AGT GGG GTC GC; backward primer: CTC GCT GAC ACA AGG GCT GCG GAC; lac-Z forward primer: CAC TAC GTC TGA ACG TCG AAA ACC CG; backward primer: CGG GCA AAT AAT ATC GGT GGC CGT GG) with annealing at $55^{\circ} \mathrm{C}$ for $1 \mathrm{~min}$ and extension at $72^{\circ} \mathrm{C}$ for $1 \mathrm{~min}$ for 30 cycles with GO TaqDNA polymerase (Promega). PCR amplification of the nAChR $\alpha 7$ subunit or AK (an indicator for the knock-out) were performed using the purified genomic DNA as template and gene-specific primer pairs ( $\alpha 7$ subunit forward primer: 5' -CCT GGT CCT GCT GTG TTA AAC TGC TTC-3'; backward primer: $5^{\prime}$-CTG CTG GGA AAT CCT AGG CAC ACT TGA G-3'; AK forward primer: 5' -CGG ATC AAG CGT ATG CAG CCG-3'; backward primer: 5' -CAA GAT GGA TTG CAC GCA GG-3') with annealing at $60^{\circ} \mathrm{C}\left(54^{\circ} \mathrm{C}\right.$ for $\mathrm{AK}$ gene) for $1 \mathrm{~min}$ and extension at $72^{\circ} \mathrm{C}$ for 1 min for 35 cycles with GO TaqDNA polymerase (Promega). PCR products were resolved using electrophoresis on $1 \%$ agarose gels and stained for visualization before images were captured using digital photography. Individuals conducting electrophysiological studies were blind with regard to knowledge about genotyping results conducted by other members of the group.

Statistical significance of the comparison between two groups of matched datasets was assessed as $p<0.05$ using two-tailed Student's $t$ test. All values are expressed as mean \pm SEM. For statistical analysis of data from multiple groups of data, one-way ANOVA followed by Fisher's PLSD post hoc test were applied. In cases where mean and SEM values evident in figures differ from those in the text, this is because values given
A Sal
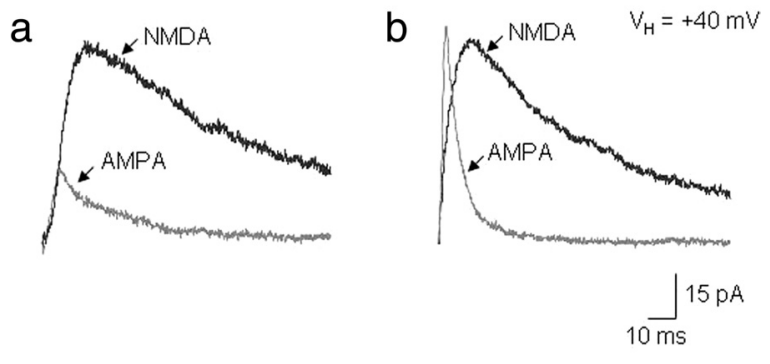

B

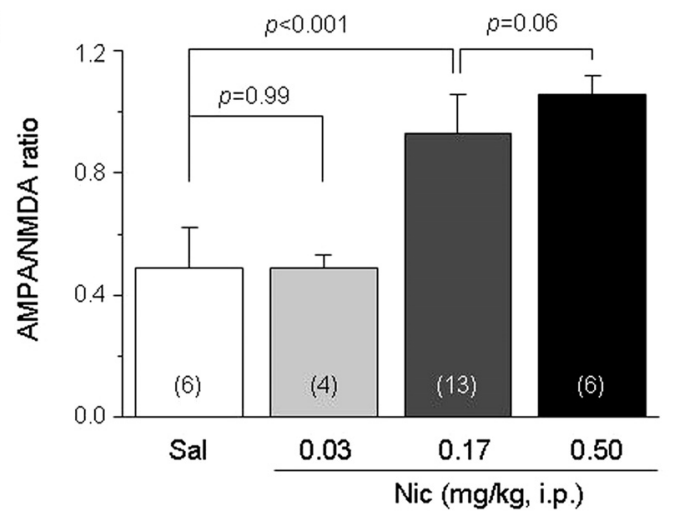

Figure 1. Single, systemic nicotine administration increases the AMPA/NMDA ratio. $\boldsymbol{A}$, Representative traces are shown for AMPA receptor- and NMDA receptor-mediated currents (indicated by arrows) in saline- or nicotine-injected rats. Patch-clamp recording was performed from DA neurons in VTA slices $24 \mathrm{~h}$ after nicotine bitartrate (Nic) (equivalent free base dose is shown) or saline (Sal)injection i.p. $\boldsymbol{B}$, A summary is shown of effects of nicotine free base delivered to achieve the indicated doses on AMPA/NMDA ratios (ordinate; mean $\pm \mathrm{SEM} ; n=$ number of cases; $t$ test results are indicated).

in the text are from complete datasets, whereas results in some figures are from data subsets. $p$ values are provided for each experimental condition unless $p<0.001$.

\section{Results}

\section{Systemic nicotine increases the AMPA/NMDA ratio in VTA} DA neurons

The initial experimental approach was based on a previously reported protocol involving in vivo delivery of cocaine followed by in vitro electrophysiological assessment of effects (Ungless et al., 2001). Nicotine bitartrate was systemically administered intraperitoneally to rats in a single injection, and $24 \mathrm{~h}$ later, horizontal midbrain slices containing the VTA were prepared for whole-cell patch-clamp recording. The identification of DA neurons in slices was based on a series of well established electrophysiological characteristics (Johnson and North, 1992; Margolis et al., 2003). For instance, VTA DA neurons exhibit spontaneous action potential firing $(1-3 \mathrm{~Hz})$ with a relatively wide spike duration $(>2.5$ ms) that is sensitive to the $\mu$-receptor agonist DAMGO, which selectively inhibits GABAergic neuron firing, in turn increasing DA neuron firing by disinhibition (supplemental Fig. 1, available at www.jneurosci.org as supplemental material). In addition, hyperpolarization-activated currents $\left(I_{\mathrm{h}}\right)$ are observed in DAergic but not GABAergic neurons, and staining for tyrosine hydroxylase confirms a DA neuronal phenotype (supplemental Fig. 1, available at www.jneurosci.org as supplemental material).

Measurements of glutamatergic synaptic strength were done exactly as previously described (Ungless et al., 2001; Saal et al., 2003), defining amplitudes of AMPA receptor-mediated EPSCs 
A

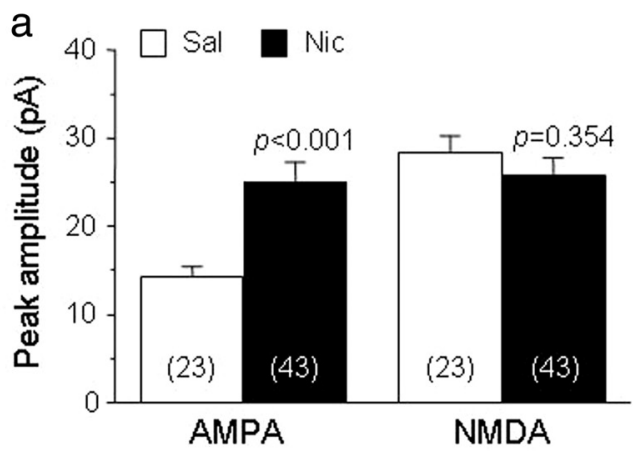

B

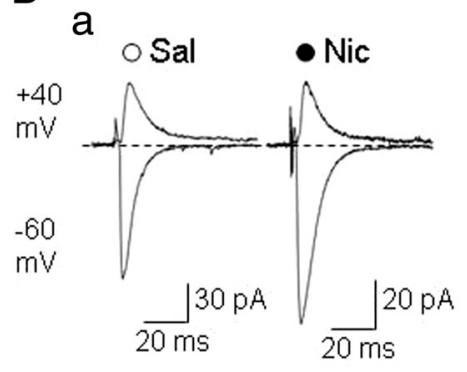

b

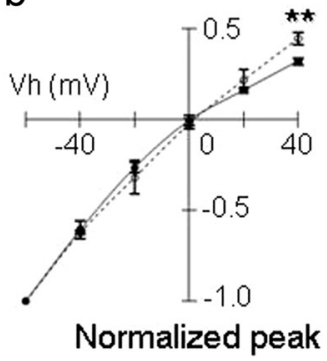

b

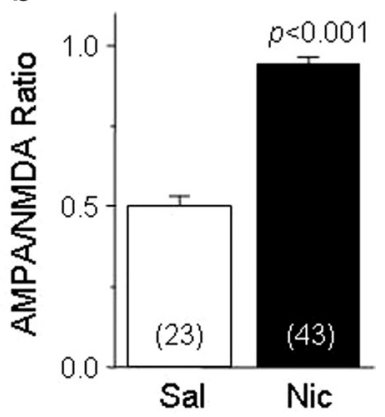

The systemic nicotine-induced increase in the AMPA/NMDA ratio is caused by an increase in postsynaptic APMA receptor function

We next sought to determine whether the systemic nicotine-induced increase in the AMPA/NMDA ratio was due to an enhancement of AMPA receptor function and/or a reduction in NMDA receptor function. The results showed that $24 \mathrm{~h}$ after systemic administration of $0.17 \mathrm{mg} / \mathrm{kg}$ nicotine free base, AMPA receptormediated current amplitudes $(25.1 \pm 2.2$ $\mathrm{pA} ; n=43)$ were significantly increased $(p<0.001)$ compared with those obtained from saline-injected rats $(14.3 \pm$

Figure 2. Systemic nicotine upregulates postsynaptic AMPA receptor function. A, AMPA receptor- and NMDA receptormediated currents [ordinate, absolute peak amplitude (pA)] were recorded in DA neurons from VTA slices obtained from nicotinetreated (Nic) $(0.17 \mathrm{mg} / \mathrm{kg}$ free base; solid bars) or saline-treated (Sal) (open bars) rats. Results show that nicotine significantly increases AMPA receptor-mediated currents $(\boldsymbol{A} \boldsymbol{a})$, which causes an increase in the AMPA/NMDA ratio $(\boldsymbol{A} \boldsymbol{b})$. $\boldsymbol{B}$, Current-voltage $(I-V)$ relationships were derived for AMPA receptor-mediated currents from DA neurons in slices from rats treated with normal saline $(\bigcirc)$ or nicotine $(0)(0.17 \mathrm{mg} / \mathrm{kg}$ free base). Recordings were done using pipette electrodes containing $100 \mu \mathrm{m}$ spermine and in the presence of bath-applied $20 \mu \mathrm{m}$ bicuculline and $100 \mu \mathrm{m} \mathrm{APV}$. Ba, Representative traces of AMPA currents at -60 and $+40 \mathrm{mV}$ holding potential $\left(V_{\mathrm{h}}\right)$. Bb, Plot of peak AMPA current amplitudes (ordinate; normalized responses obtained at $-60 \mathrm{mV}$ $V_{\mathrm{h}}$ ) as a function of holding potential $(\mathrm{mV})$ shows inward rectification at positive holding potentials. $B \boldsymbol{C}$, Comparison of peak AMPA current amplitudes at -60 and $+40 \mathrm{mVV} V_{\mathrm{h}}\left(I_{-60 \mathrm{mv}} / I_{+40 \mathrm{mv}}\right.$; ordinate) shows enhanced inward rectification after nicotine (solid bar) relative to saline (open bar) exposure. ${ }^{* *} p<0.01$.

relative to amplitudes of NMDA receptor-mediated EPSCs (calculated as fractions of evEPSCs showing insensitivity or sensitivity to block by the NMDA receptor antagonists D-APV and in the presence of the $\mathrm{GABA}_{\mathrm{A}}$ receptor antagonist picrotoxin to block inhibitory responses) to obtain the so-called AMPA/NMDA ratio (Fig. $1 A$ ). Nicotine administration was done to achieve nicotine bitartrate doses of $0.1,0.5$ or $1.5 \mathrm{mg} / \mathrm{kg}$, equivalent to $0.033,0.17$ and $0.5 \mathrm{mg} / \mathrm{kg}$ free-base nicotine, and AMPA/NMDA ratios determined $24 \mathrm{~h}$ later were $0.49 \pm 0.04(n=4), 0.93 \pm 0.05(n=13)$ or $1.06 \pm 0.06(n=6)$, respectively (Fig. $1 B)$. The AMPA/NMDA ratio was $0.48 \pm 0.05(n=6)$ in the saline-treated, control group. There was a significant difference in the AMPA/NMDA ratios among the four groups (ANOVA, $F_{(3,25)}=30.69, p<0.001$ ). Injection of $0.033 \mathrm{mg} / \mathrm{kg}$ nicotine (free base) failed to increase the AMPA/NMDA ratio relative to the result for the saline-treated group (Fisher's PLSD post hoc test, $p=0.992$ ), but exposure to either 0.17 or $0.5 \mathrm{mg} / \mathrm{kg}$ nicotine significantly increased the AMPA/NMDA ratio (Fisher's PLSD post hoc tests, $p<0.001$; Fig. $1 C)$. These results are consistent with a previous report that a single, systemic administration of nicotine $(0.5 \mathrm{mg} / \mathrm{kg}$ of what we presume to have been free base nicotine) enhances the AMPA/ NMDA ratio on VTA DA neurons $24 \mathrm{~h}$ later (Saal et al., 2003), but we also show that a lower dose of $0.17 \mathrm{mg} / \mathrm{kg}$ free-base nicotine is sufficient to increase the AMPA/NMDA ratio. We used the lower dose of $0.17 \mathrm{mg} / \mathrm{kg}$ nicotine free base unless otherwise indicated.

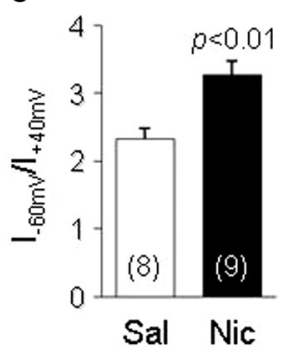

$1.2 \mathrm{pA} ; n=23)$, whereas there was no effect of nicotine on amplitudes of NMDA receptor-mediated currents (saline group: $28.4 \pm 1.9 \mathrm{pA}, n=23$; nicotine group: $25.9 \pm 1.9 \mathrm{pA}, n=43 ; p=0.354$ ) (Fig. $2 \mathrm{Aa}$ ). These results translated again into an increase in the AMPA/NMDA ratio after nicotine exposure (Fig. $2 A b$ ) and are consistent with a specific upregulation of AMPA receptor function by nicotine exposure that persists for at least $24 \mathrm{~h}$.

To further illuminate processes involved in the increase in AMPA receptor function, we compared current-voltage $(I-V)$ relationships for AMPA receptormediated currents in slices from saline- or nicotine-treated rats. These studies were done using pipette electrodes filled with solutions supplemented to a final concentration of $100 \mu \mathrm{M}$ spermine, which is a voltage-dependent, functional inhibitor of AMPA receptors containing GluR1 subunits and lacking GluR2 subunits (Argilli et al., 2008). This strategy has been used previously to show that exposure to cocaine promotes increases in postsynaptic membrane levels of GluR1-(non-GluR2)-AMPA receptors, which show heightened inward rectification due to functional block by spermine at positive holding potentials relative to spermine-insensitive responses of GluR2-AMPA receptors (Argilli et al., 2008). These studies also were done with $20 \mu \mathrm{M}$ bicuculline to block $\mathrm{GABA}_{\mathrm{A}}$ receptors and $100 \mu \mathrm{M}$ D-APV to block NMDA receptors so that AMPA receptor responses could be isolated. The results show that there is heightened inward rectification of AMPA currents after nicotine treatment (Fig. $2 B$ ) exemplified by a significantly smaller amplitude of AMPA current only at $+40 \mathrm{mV}$ holding potential $\left(V_{\mathrm{H}}\right)(14.5 \pm$ $3.1 \mathrm{pA}, n=9)$ relative to those obtained from saline-treated animals $(22.7 \pm 3.6 \mathrm{pA}, n=8$; $p<0.01$, Fig. $2 \mathrm{Bb})$ and a higher ratio of peak current amplitude at $-60 \mathrm{mV}$ as opposed to +40 $\mathrm{mV}(p<0.01$; Fig. $2 \mathrm{Bc}$ ). These results suggest that new AMPA receptors containing GluR1 but not GluR2 subunits contribute to functional responses $24 \mathrm{~h}$ after nicotine administration.

The time course for the systemic nicotine-induced increase in the AMPA/NMDA ratio

Previous reports showed that a single, systemic exposure to nicotine rapidly increased behavioral activity and DA release in the nucleus accumbens to a maximal level within $30 \mathrm{~min}$ after drug 

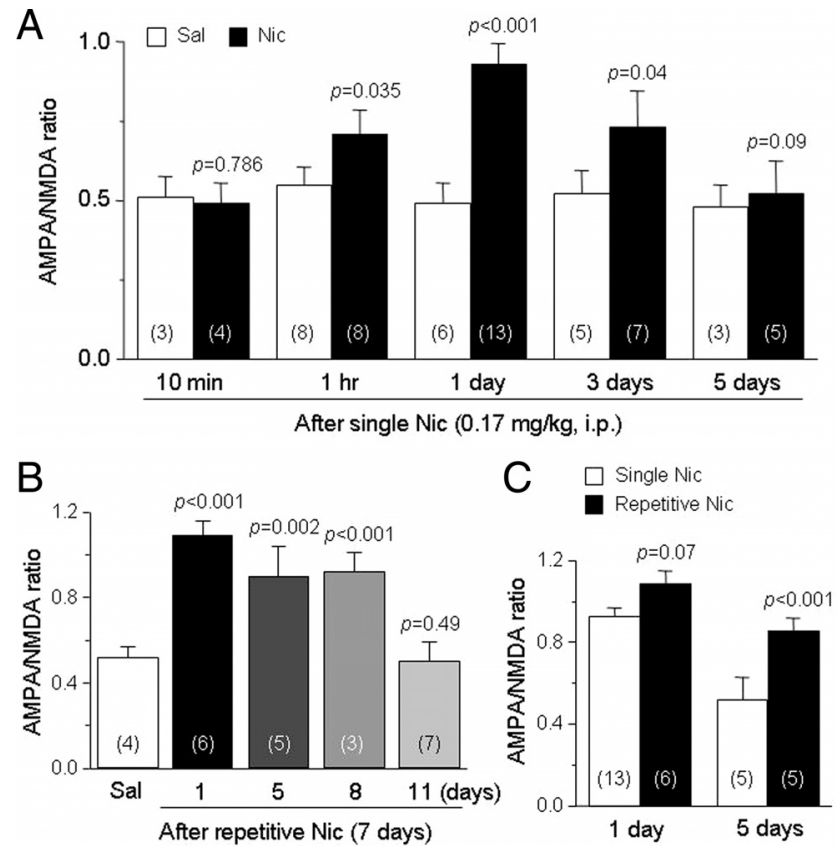

Figure 3. Time course for nicotine-induced increases in AMPA/NMDA ratios. $\boldsymbol{A}$, AMPA/NMDA ratios were measured on DA neurons in rat VTA slices at the times indicated after a single nicotine injection (Nic) $(0.17 \mathrm{mg} / \mathrm{kg}$ free base, i.p.; solid bars) or saline injection (Sal) (open bars). Nicotine treatment increases AMPA/NMDA ratios measured 1, 24, or $72 \mathrm{~h}$ but not $10 \mathrm{~min}$ or 5 d after injection. $\boldsymbol{B}$, AMPA/NMDA ratios were assessed at the indicated times after repeated, once-daily injections with nicotine $(0.17 \mathrm{mg} / \mathrm{kg}$ free base, i.p.) for $7 \mathrm{~d}$. There was an increase in AMPA/NMDA ratios at 1, 5, or $8 \mathrm{~d}$ but not $11 \mathrm{~d}$ after the last nicotine injection. C, Comparisons of nicotine treatment effects on AMPA/NMDA ratios measured 1 or $5 \mathrm{~d}$ after a single injection of nicotine (open bars) or 1 or $5 \mathrm{~d}$ after the last of seven, once-daily injections of nicotine. Results show that repeated administration is required to maintain the change in glutamatergic response for $5 \mathrm{~d}$.

delivery and that there then was a gradual decrease in those measures to baseline levels within $1 \mathrm{~h}$ after nicotine exposure (Benwell and Balfour, 1992). As a step to test for possible relationships between changes in AMPA/NMDA ratios and behavioral activity/DA release, we examined the time course for nicotinic effects on AMPA/NMDA ratios at 10 or 60 min or at 1 , 3 , or $5 \mathrm{~d}$ after a single injection of nicotine $(0.17 \mathrm{mg} / \mathrm{kg}$ free base, i.p.). The AMPA/NMDA ratio was not significantly altered 10 min after injection of nicotine $(0.56 \pm 0.13, n=4)$ relative to the ratio for saline-treated controls $(0.51 \pm 0.12, n=3 ; p=0.786)$. However, AMPA/NMDA ratios were significantly increased at $1 \mathrm{~h}$ (nicotine: $0.71 \pm 0.05, n=8$; compared with saline: $0.55 \pm$ $0.04, n=8 ; p<0.035), 24 \mathrm{~h}$ (nicotine $=0.93 \pm 0.05, n=13$; saline: $0.48 \pm 0.05, n=6 ; p=0.001$ ) and $72 \mathrm{~h}$ (nicotine: $0.73 \pm$ $0.23, n=7$; saline: $0.52 \pm 0.15, n=5 ; p=0.040)$ after systemic nicotine injection (Fig. $3 A$ ). The increased AMPA/NMDA ratio was most pronounced at $24 \mathrm{~h}$ after a single injection of nicotine, but the effect was absent $5 \mathrm{~d}(120 \mathrm{~h})$ following nicotine injection (nicotine: $0.52 \pm 0.11, n=5$ vs saline: $0.48 \pm 0.08, n=3, p=$ 0.094). AMPA/NMDA ratios did not significantly differ when assessed as soon as $10 \mathrm{~min}$ or as long as $5 \mathrm{~d}$ after a single saline injection (Fig. 3A). These results indicate that a single, systemic exposure to nicotine increases the AMPA/NMDA ratio in VTA DA neurons within $1 \mathrm{~h}$ and that this increase lasts for at least $72 \mathrm{~h}$ after nicotine exposure.

Additional studies were done to determine effects of repeated administration of nicotine (once daily for $7 \mathrm{~d} ; 0.17 \mathrm{mg} / \mathrm{kg} / \mathrm{d}$ free base, i.p.), which is known to induce both behavioral sensitiza- tion and alterations in DA and glutamate transmission as well as glutamatergic synaptic plasticity (Vezina et al., 2007). When measured $1,5,8$, or $11 \mathrm{~d}$ after the last of the seven, once-daily injections of nicotine, the AMPA/NMDA ratios were $1.09 \pm 0.06$ $(n=6), 0.86 \pm 0.06(n=5), 0.93 \pm 0.07(n=3)$ and $0.51 \pm 0.01$ $(n=7)$, respectively. Relative to the AMPA/NMDA ratio (ratio: $0.52 \pm 0.09, n=4$ ) for the saline-treated group (once daily injections for $7 \mathrm{~d}$ and AMPA/NMDA ratio assessment $1 \mathrm{~d}$ later on day 8), repetitive injection of nicotine significantly increased the AMPA/NMDA ratio measured $1 \mathrm{~d}(p<0.001), 5 \mathrm{~d}(p=0.021)$, or 8 d later $(p=0.01)$ (ANOVA, $\left.F_{(4,18)}=28.35, p<0.001\right)$, but not $11 \mathrm{~d}$ after the final nicotine injection (the AMPA/NMDA ratio declined back to baseline levels, $p=0.666$; Fig. $3 B$ ). Based on the values already provided, there was no significant difference between AMPA/NMDA ratios measured $1 \mathrm{~d}$ after a single injection or $1 \mathrm{~d}$ after the last of seven daily injections of nicotine ( $p=0.072$, Fig. $3 C$ ). However, whereas the increase in AMPA/ NMDA ratio was lost $5 \mathrm{~d}$ after a single nicotine injection $(0.52 \pm$ $0.11, n=5)$, effects persisted for $5(0.86 \pm 0.06, n=5, p<0.001$; Fig. $3 C$ ) and even $8 \mathrm{~d}$ after repeated nicotine injections. These results suggest that nicotine-induced glutamatergic synaptic plasticity on VTA DA neurons is an early neural adaptation, that its initiation does not require repetitive exposures to nicotine, but that repetitive exposures to nicotine produce a more persisting effect.

\section{nAChR subtypes that mediate systemic nicotine-induced} increase in the AMPA/NMDA ratio in VTA DA neurons

Nicotine exerts its pharmacological and biological effects through actions on nAChRs. In the VTA, the predominant nAChR subtypes are $\alpha 4 \beta 2$ - and $\alpha 7$-nAChRs (Klink et al., 2001; Nashmi et al., 2007; Yang et al., 2009). To test which nAChR subtype(s) mediate(s) the systemic nicotine-induced increase in the AMPA/NMDA ratio, we administered antagonists selective for $\alpha 7$ - or $\beta 2^{\star}$-nAChR (where the ${ }^{*}$ indicates that nAChR subunits in addition to those specified are known or possible components of the assembly) at doses shown in previous studies to be effective $10 \mathrm{~min}$ before a single, systemic injection of $0.17 \mathrm{mg} / \mathrm{kg}$ free base nicotine (Walters et al., 2006; Zanetti et al., 2006). Surprisingly, a $10 \mathrm{~min}$ preexposure to either the $\alpha 7-\mathrm{nAChR}$-selective antagonist MLA ( $5 \mathrm{mg} / \mathrm{kg}$, i.p.) or the $\beta 2^{\star}-\mathrm{nAChR}$ antagonist MEC ( $3 \mathrm{mg} / \mathrm{kg}$, i.p.) failed to prevent the nicotine-induced increase in the AMPA/NMDA ratio measured $24 \mathrm{~h}$ later (Fig. $4 \mathrm{~A}$ ). AMPA/NMDA ratios were $0.93 \pm 0.05(n=13), 1.00 \pm 0.03(n=$ $11)$ or $0.88 \pm 0.02(n=15)$ for the saline-nicotine, MLA-nicotine or MEC-nicotine groups, respectively (Fig. $4 B$ ). There were no significant differences in AMPA/NMDA ratios relative to the saline-nicotine positive control for the MLA-nicotine group $(p=0.186)$ or for the MEC-nicotine group $(p=0.288)$. All three groups differed $(p<0.001)$ from their respective negative controls (saline-saline, MLA-saline, MEC-saline), which were essentially equivalent and showed no effect of either antagonist alone on basal AMPA/NMDA ratios (Fig. $4 B$, open bars). However, coadministration of both MLA and MEC for $10 \mathrm{~min}$ before nicotine injection abolished the effect seen $24 \mathrm{~h}$ after nicotine exposure alone (AMPA/NMDA ratio for MLA+MEC-nicotine: $0.53 \pm 0.06, n=8 ; p<0.001$ relative to the saline-nicotine group; $p=0.599$ relative to the MLA+MEC-saline group) (Fig. 4). These results suggest that the activation of either $\alpha 7$ - or $\beta 2^{\star}$ $\mathrm{nAChR}$ by systemic nicotine is sufficient to trigger a maximal increase in AMPA/NMDA ratio in VTA DA neurons and that both $\mathrm{nAChR}$ subtypes need to be blocked to abolish glutama- 
A
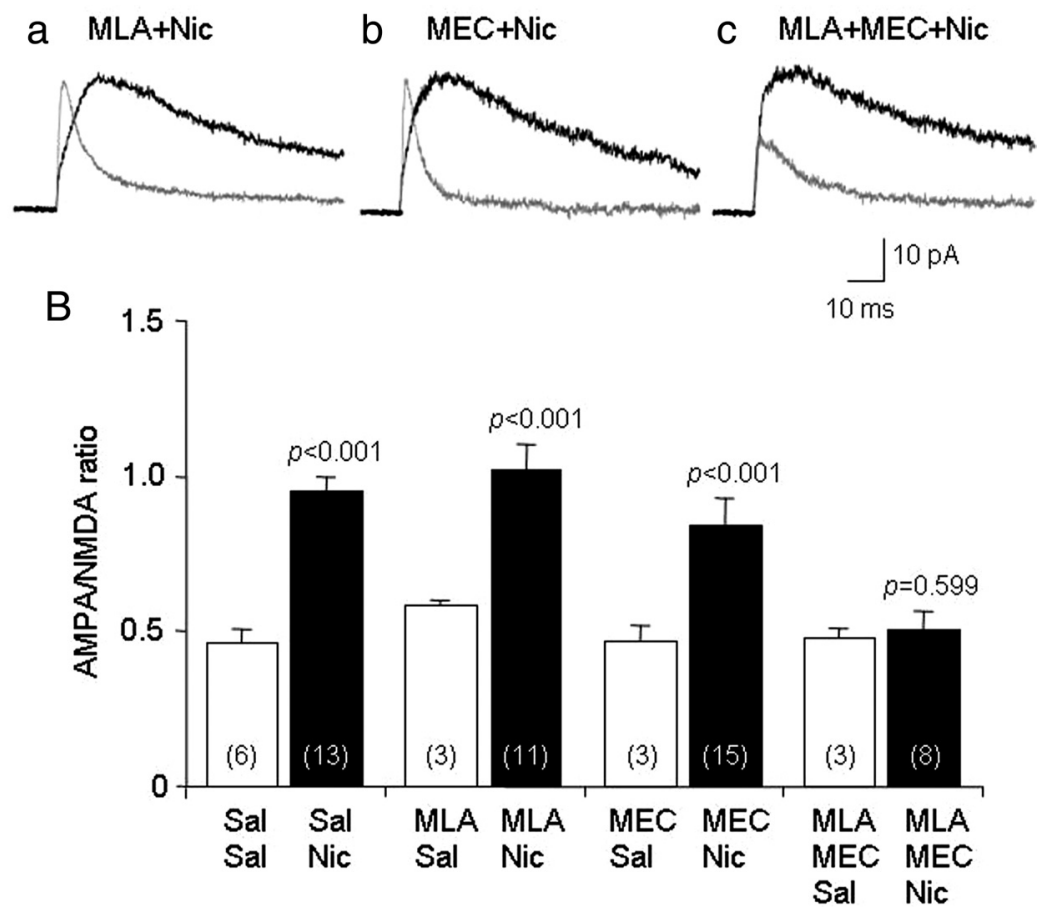

Figure 4. $n A C h R$ subtypes that mediate the systemic nicotine-induced increase in the AMPA/NMDA ratio. $A$, Representative traces are shown for AMPA (thin) and NMDA (thick) receptor-mediated currents measured on DA neurons from rat VTA slices prepared $24 \mathrm{~h}$ after animals were injected to achieve doses of $5.0 \mathrm{mg} / \mathrm{kg} \mathrm{MLA}, 3.0 \mathrm{mg} / \mathrm{kg} \mathrm{MEC}$, or both $10 \mathrm{~min}$ before treatment via a single injection with nicotine (Nic) $(0.17 \mathrm{mg} / \mathrm{kg}$ free base, i.p.). B, Summary of effects of pretreatment with $\alpha 7-\mathrm{nAChR}$ (MLA) and/or $\beta 2^{*}$-nAChR (MEC) antagonists on systemic nicotine (solid bars)-induced increases in AMPA/NMDA ratios. Results also are shown for effects or antagonist pretreatment on AMPA/NMDA ratios after negative control saline (Sal) (open bars) injection. Neither MLA nor MEC alone inhibits the nicotine-induced increase in the AMPA/NMDA ratio. However, coadministration of MLA and MEC completely abolishes the nicotine-induced increase in the AMPA/NMDA ratio. Antagonists have no significant effects alone or when combined in saline-treated animals. Statistical comparisons between saline and nicotine conditions are presented above each solid bar, and statistical comparisons across saline or nicotine groups are presented in the narrative.

tergic synaptic plasticity induced by a single, systemic nicotine exposure.

\section{Effects of systemic injection of nicotine on AMPA/NMDA} ratios in VTA DA neurons from $\mathrm{nAChR} \alpha 7$ and $\beta 2 \mathrm{KO}$ mice To complement pharmacological studies, we used nAChR $\alpha 7$ or $\beta 2$ subunit KO mice to evaluate roles of $\alpha 7$ - or $\beta 2^{\star}-\mathrm{nAChR}$ in nicotinic effects on AMPA/NMDA ratios. A single, systemic injection of nicotine $(0.17 \mathrm{mg} / \mathrm{kg}$ free base, i.p.) produced an increase in the AMPA/NMDA ratio measured $24 \mathrm{~h}$ later (relative to the ratio for control, saline groups) for WT mice (saline $0.52 \pm$ $0.04, n=6$; nicotine $0.82 \pm 0.05, n=7 ; p<0.001), \alpha 7$ subunit $\mathrm{KO}$ mice ( $\alpha 7 \mathrm{KO}$ : saline $0.45 \pm 0.03, n=6$; nicotine $0.93 \pm 0.08$, $n=6, p=0.006)$, or $\beta 2$ subunit $\mathrm{KO}$ mice $(\beta 2 \mathrm{KO}$ : saline $0.67 \pm$ $0.02, n=5$; nicotine $0.96 \pm 0.06, n=7, p=0.002$ ) (Fig. $5 A, B$ ). Differences in nicotine-induced increases in AMPA/NMDA ratios across WT, $\alpha 7$ or $\beta 2 \mathrm{KO}$ mice are not significant (WT vs $\alpha 7$ KO mice, $p=0.155$; WT vs $\beta 2 \mathrm{KO}$ mice, $p=0.527 ; \alpha 7$ vs $\beta 2 \mathrm{KO}$ mice, $p=0.738$ ). These results are consistent with pharmacological data and suggest that the increase in the AMPA/NMDA ratio in VTA DA neurons following systemic administration of nicotine is mediated redundantly, in that it is present in the genetic absence or upon pharmacological block of either $\alpha 7$ - or $\beta 2^{\star}$ $\mathrm{nAChR}$. Interestingly, compared with saline-treated WT mice $(0.57 \pm 0.02, n=6)$, saline-treated $\beta 2 \mathrm{KO}$ mice $(0.67 \pm 0.02, n=$ $5)$ exhibited a significantly higher AMPA/NMDA ratio $(p=$ $0.008)$, suggesting that the elimination of $\beta 2^{\star}-\mathrm{nAChR}$ may affect
AMPA receptor expression and function in VTA DA neurons (Fig. 5B). To further examine the basis for these effects, we determined absolute values for AMPA and NMDA peak current amplitudes and found no significant differences in effects of nicotine exposure across WT, $\alpha 7 \mathrm{KO}$ or $\beta 2 \mathrm{KO}$ mice (AMPA peak current amplitude: ANOVA, $F_{(2,14)}=1.59, p=0.24$; NMDA peak current amplitude: ANOVA, $\left.F_{(2,14)}=2.86, p=0.09\right)$ (Fig. 5C).

Roles of other entities in effects of systemic nicotine on the AMPA/NMDA ratios in VTA DA neurons

To define some of the many possible cellular and molecular entities participating in effects of systemic nicotine on AMPA/ NMDA ratios, we tested the abilities of selected agents to block those effects when given before nicotine administration in vivo (Fig. 6). ANOVA analysis demonstrated a significant difference among four groups $\left(F_{(3,26)}=11.64, p<0.001\right.$; Fig. $6 B$ ) Treatment with the NMDA receptor antagonist MK-801 (1.0 mg/kg) 10 min before a single injection with nicotine $(0.17 \mathrm{mg} / \mathrm{kg}$, i.p.) abolished the nicotineinduced increase in AMPA/NMDA ratio (MK-801-nicotine: $0.51 \pm 0.06, n=7$; saline-nicotine: $0.93 \pm 0.05, n=13 ; p<$ 0.001) assessed $24 \mathrm{~h}$ later (Fig. 6B). By contrast, neither DA receptor antagonists given $10 \mathrm{~min}$ before nicotine $(1 \mathrm{mg} / \mathrm{kg}$ SCH-23390 plus $2 \mathrm{mg} / \mathrm{kg}$ haloperidolnicotine: $\mathrm{AMPA} / \mathrm{NMDA}$ ratio $=0.92 \pm$ $0.11, n=4 ; p=0.844)$ nor a calcineurin inhibitor given $90 \mathrm{~min}$ before nicotine $(15 \mathrm{mg} / \mathrm{kg}$ cyclosporine-nicotine: AMPA/NMDA ratio $=1.01 \pm 0.09, n=6 ; p=0.272)$ prevented the nicotineinduced increase in AMPA/NMDA ratio (Fig. $6 B$ ). These results suggest that systemic nicotine increases the AMPA/NMDA ratio via mechanisms that require activation of NMDA receptors but not via processes that require activity of DA receptors or calcineurin-dependent signaling.

\section{Effects of systemic nicotine exposure on glutamatergic and} GABAergic transmission onto VTA DA neurons

We next asked whether the nicotine exposure-induced increase in AMPA/NMDA ratio in rat VTA DA neurons could be caused by alterations of excitatory and/or inhibitory neurotransmission. For analyses of excitatory neurotransmission, measures were made in current-clamp mode of EPSP responses to presynaptic paired-pulse stimuli at an interpulse interval of $50 \mathrm{~ms}$ (Pu et al., $2006)$ in the presence of the $\mathrm{GABA}_{\mathrm{A}}$ receptor antagonist picrotoxin $(100 \mu \mathrm{M})$ to ensure elimination of stimulation-induced effects on inhibitory neurotransmission. The recordings were performed $10 \mathrm{~min}$ or 1 or $24 \mathrm{~h}$ after systemic nicotine injection $(0.17 \mathrm{mg} / \mathrm{kg}$ free base, i.p.). The EPSP PPR (P2/P1) was significantly decreased in slices from nicotine-treated (Fig. $7 B$ ) relative to saline-treated (Fig. $7 A$ ) rats, and effects were evident at all tested time points after nicotine injection (Fig. 7C). EPSP PPR values were $1.34 \pm 0.03(n=6)$ for nicotine-treated and $1.87 \pm$ $0.04(n=6)$ for saline-injected $(p<0.001)$ rats when assessed 10 
min later, $1.40 \pm 0.03(n=8)$ for nicotine-injected and $1.80 \pm 0.03(n=4)$ for saline-treated $(p<0.001)$ animals when determined $1 \mathrm{~h}$ later, and $1.40 \pm$ $0.05(n=8)$ for nicotine treatment and $2.40 \pm 0.09(n=4)$ for saline treatment $(p<0.001)$ when defined 24 h later. These results suggest that there is an increase in the probability of presynaptic glutamate release following systemic nicotine exposure.

Since it is known that GABA-mediated inhibition suppresses induction of longterm potentiation at many excitatory synapses (Wigström and Gustafsson, 1983; Huang et al., 1999; Bissière et al., 2003; Meredith et al., 2003), we tested whether systemic exposure to nicotine alters GABAergic transmission. We examined IPSCs under voltage-clamp conditions evoked by paired-pulse stimuli at an interpulse interval of $50 \mathrm{~ms}$ at a $V_{\mathrm{H}}$ of $-20 \mathrm{mV}$ in the presence of NBQX $(10 \mu \mathrm{M})$ and D-APV $(50 \mu \mathrm{M})$ to block glutamate receptor responses (Liu et al., 2005). Stimulation intensity was gradually increased until threshold for production of IPSCs was reached, and then we used double threshold intensity stimulation to reliably induce IPSCs. Effects on IPSCs were determined $10 \mathrm{~min}$ or 1 or $24 \mathrm{~h}$ after systemic administration of nicotine or saline. The results showed that there was no significant change in the IPSC $\mathrm{P} 2 / \mathrm{P} 1$ ratio between nicotine-treated (Fig. $8 A$ ) and saline-injected (Fig. $8 B$ ) rats at any of the tested time-points, suggesting that systemic exposure to nicotine does not alter the probability of presynaptic GABA release.

\section{Effects of systemic nicotine on miniature EPSCs and IPSCs in VTA DA neurons}

The PPR experiments suggested that systemic nicotine exposure may affect presynaptic glutamate but not GABA release. To further test this possibility, we measured miniature EPSCs (mEPSCs) and IPSCs (mIPSCs) in VTA DA neurons (Thomas et al., 2001; Ungless et al., 2001; Pu et al., 2006; Heikkinen et al., 2009) prepared from slices taken from and subjected to voltage-clamp recording $24 \mathrm{~h}$ after rats were injected with nicotine $(0.17 \mathrm{mg} / \mathrm{kg}$ free base equivalent, i.p. $)$ or saline. The amplitude of mEPSCs was significantly increased in neurons from nicotine-treated animals when compared with results from the saline group (nicotine group: $18.8 \pm 1.3 \mathrm{pA}, n=12$; saline group: $14.6 \pm 1.1 \mathrm{pA}, n=8 ; p=0.022$ ) (Fig. 9Ca). However, mEPSC frequency was not significantly altered (nicotine group: $1.5 \pm 0.4 \mathrm{~Hz}, n=12$; saline group: $2.1 \pm 0.7 \mathrm{~Hz}, n=8 ; p=0.487$ ) (Fig. 9Cb). There was no effect of nicotine exposure on either mIPSC amplitude (Fig. 9Da) or frequency (Fig. 9Db). These results suggest that $24 \mathrm{~h}$ after systemic injection of nicotine, the major alteration is an increase in glutamatergic transmis- sion manifest both as an enhancement of postsynaptic AMPA receptor numbers/function and evident from an increase in the AMPA/NMDA ratio and in mEPSC amplitude.

\section{Systemic nicotine increases VTA DA neuronal firing in vivo} A logical hypothesis based on the data presented above is that systemic exposure to nicotine produces a long-lasting increase in DA neuron firing due to its enhancement of both presynaptic glutamate release and postsynaptic AMPA receptor expression/ function. To test this hypothesis, we performed in vivo extracellular recordings in anesthetized rats of the same age used in slicepatch studies to measure VTA DA neuronal activity $24 \mathrm{~h}$ after a single exposure to nicotine $(0.17 \mathrm{mg} / \mathrm{kg}$ free base, i.p.) or saline (Fig. 10A). Relative to findings in saline-treated controls, nicotine administration decreased the power of slow oscillations 
A MK-801+Nic

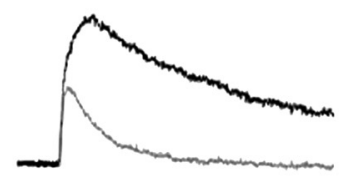

$\mathrm{Hal}+\mathrm{SCH}-23390+\mathrm{Nic}$
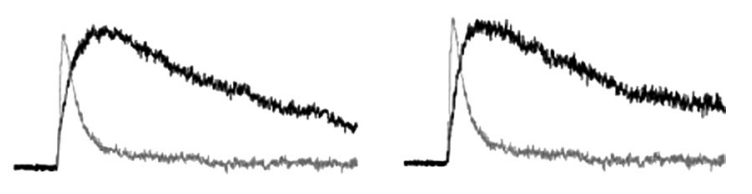

$\underset{10 \mathrm{~ms}}{\longrightarrow} 10 \mathrm{pA}$

B

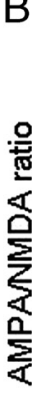

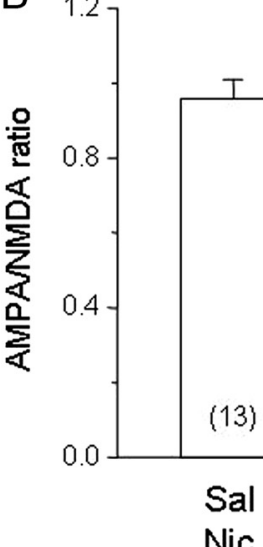

(13)

Sal
Nic

Figure 6. Pharmacological dissection of events involved in the nicotine-induced increase in the AMPA/NMDA ratio. $\boldsymbol{A}$, Representative traces are shown for AMPA (thin) and NMDA (thick) receptor-mediated currents measured on DA neurons from rat VTA slices prepared $24 \mathrm{~h}$ after animals were given a single injection of nicotine (Nic) $(0.17 \mathrm{mg} / \mathrm{kg}$ free base, i.p.). B, Summary of effects of treatment before nicotine injection with MK-801 (1.0 mg/kg; 10 min pretreatment), $2 \mathrm{mg} / \mathrm{kg}$ haloperidol (Hal) plus $1 \mathrm{mg} / \mathrm{kg}$ SCH-23390 (10 min pretreatment), or $15 \mathrm{mg} / \mathrm{kg}$ cyclosporine (90 min pretreatment) on the AMPA/NMDA ratio. The $p$ values compare the relevant results to those after positive control, saline-nicotine treatment.

(mean power between $0.5-1.5 \mathrm{~Hz}$ ) (Gao et al., 2007) (nicotine: $0.30 \pm 0.05, n=47$; saline: $0.51 \pm 0.07, n=48 ; p=0.021$ ) (Fig. $10 B, C$ ) and increased the firing rate of VTA DA neurons (nicotine: $4.2 \pm 0.2$ spikes/s, $n=47$; saline: $3.6 \pm 0.3$ spikes $/ \mathrm{s}, n=48$; $p=0.036$ ) (Fig. 9C). However, the percentage of VTA DA neurons showing bursting activity was not significantly different when assessed $24 \mathrm{~h}$ after nicotine or saline injection (saline: $20.3 \pm 3.0 \%$; nicotine: $19.4 \pm 2.3 \% ; p=0.815$ ). Coefficients of variability $(\mathrm{CVs})$ in interspike intervals also were not different (saline: $63.5 \pm 2.9 \%$; nicotine: $57.4 \pm 2.9 \%$; $p=0.165$ ) (Fig. $10 C)$. Interestingly, numbers of firing DA cells in each recording track were significantly increased $24 \mathrm{~h}$ after nicotine injection when compared with saline-treated controls (nicotine: $1.5 \pm 0.1$ cells/track, $n=47$; saline: $1.0 \pm 0.1$ cells/track, $n=48 ; p=0.003$, Fig. 10C). These results are consistent with the hypothesis that a single, systemic exposure to nicotine inducing an increase in glutamatergic transmission (increased presynaptic glutamate release and postsynaptic AMPA receptor function) is sufficient to produce a long-lasting (at least for $24 \mathrm{~h}$ ) increase in DA neuron firing.

\section{Discussion}

A novel and important finding from the current study is that a single, systemic exposure to nicotine in vivo rapidly (within $1 \mathrm{~h}$ ) induces long-lasting (at least for $3 \mathrm{~d}$ ) plasticity of excitatory synapses on rodent VTA DA neurons as subsequently measured in vitro using slice-patch recording. Also new, based on pharmacological and genetic approaches, are findings that these effects are mediated by either $\alpha 7$ - or $\beta 2^{\star}$-nAChRs, depend on activity of MK-801-sensitive NMDA receptors, and reflect apparent in- creases in postsynaptic expression/function of AMPA receptors containing GluR1 subunits. In addition, we show for the first time that a single, systemic administration of nicotine enhances glutamatergic transmission but not GABAergic neurotransmission. We also show that even longer-lasting effects on glutamatergic synaptic plasticity occur after cessation of repeated nicotine injections. Moreover, even for a single nicotine injection, the increase in excitatory transmission correlates with increases in DA neuronal firing rates and the number of active DA neurons measured $24 \mathrm{~h}$ later using single-unit recordings. Collectively, these findings are significant because they reveal important and novel insights into how nicotine exposure can alter function of cells and a brain region important to drug reward, reinforcement and dependence, with potential therapeutic ramifications.

\section{Systemic injection of nicotine enhances AMPA/NMDA ratio in VTA \\ DA neurons}

The finding that a single injection of nicotine produces an increase in the AMPA/ NMDA ratio, considered to be an index of long-term potentiation, on VTA DA neurons $24 \mathrm{~h}$ later is consistent with a previous report (Saal et al., 2003). In addition, we have extended previous work by defining effects on AMPA/NMDA ratios of different doses of nicotine and time courses for those effects following different regimens of nicotine administration. We clearly demonstrated that 0.17 and 0.5 (but not 0.03 ) $\mathrm{mg} / \mathrm{kg}$ nicotine free base induced a similar increase in the AMPA/NMDA ratio. Repetitive administrations of nicotine $(0.17 \mathrm{mg} / \mathrm{kg}$ daily for $7 \mathrm{~d}$ ) also induced the same increase in AMPA/NMDA ratio assessed $24 \mathrm{~h}$ later as a single administration, but the nicotinic effect lasted longer (up to 8 as opposed to $3 \mathrm{~d}$ ) after repetitive exposure. The time course for nicotine-induced increases in AMPA/ NMDA ratios showed that effects were not manifest 10 min after drug treatment but were evident within $1 \mathrm{~h}$. This contrasts with results obtained entirely in vitro showing that bath-perfusion of nicotine for $200 \mathrm{~s}$ plus postsynaptic depolarization induces LTP in glutamatergic synapses of VTA DA neurons (Mansvelder and McGehee, 2000), suggesting that systemic nicotine requires a longer time to initiate its modulation of the AMPA/NMDA ratio.

\section{Roles of $\mathrm{nAChR}$ subtypes in the mediation of systemic} nicotine-induced increase in AMPA/NMDA ratio

Pharmacological experiments demonstrated that the blockade of either $\alpha 7$-nAChRs (MLA-sensitive) or $\beta 2^{*}$-nAChRs (MECsensitive) failed to prevent the systemic nicotine-induced increase in the AMPA/NMDA ratio, but coadministration of MLA and MEC completely abolished this nicotinic effect. Similarly, pharmacological blockade of either $\alpha 7$ - or $\beta 2^{\star}$-nAChR failed to prevent cocaine-induced DA release, but the blockade of both nAChR subtypes prevented cocaine's effect (Zanetti et al., 2006). This indicates that systemic injection of nicotine acts on either $\alpha 7$ - or $\beta 2^{\star}$-nAChRs to trigger glutamatergic synaptic plasticity. 

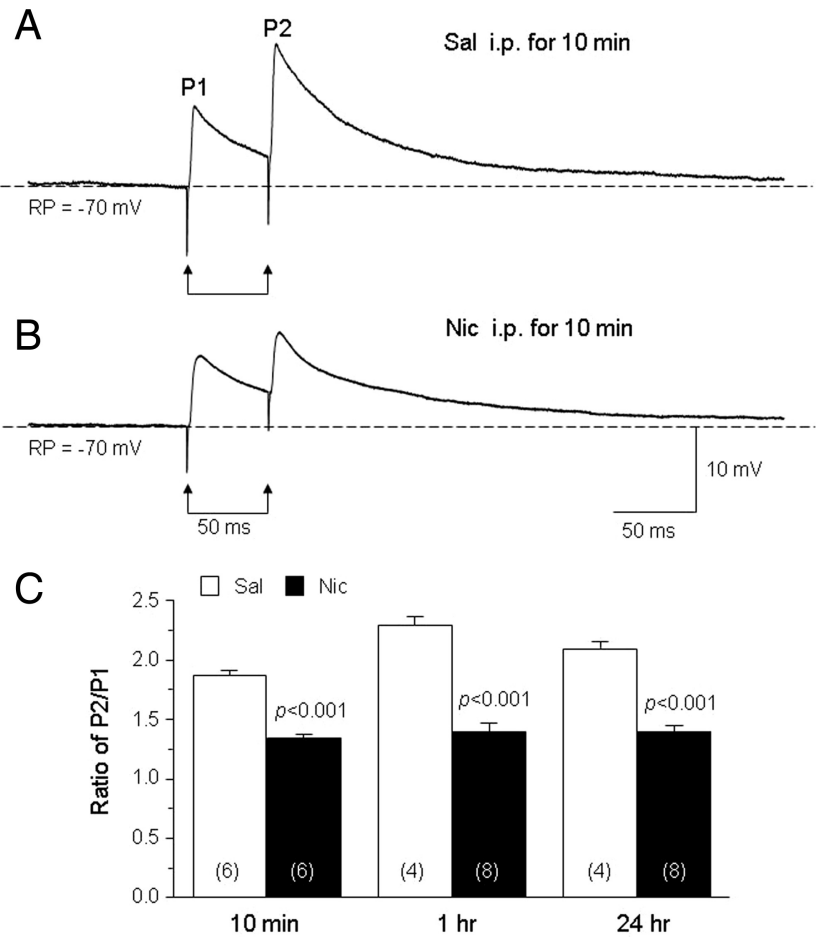

Figure 7. Effects of systemic nicotine exposure on EPSPS. $\boldsymbol{A}, \boldsymbol{B}$, Representative traces are shown for paired-pulse stimulation at an interpulse interval of $50 \mathrm{~ms}$ of EPSPs recorded from DA neurons in rat VTA slices. Slices were prepared $10 \mathrm{~min}$ after animals were given a single injection of saline (Sal) (A) or nicotine (Nic) $(0.17 \mathrm{mg} / \mathrm{kg}$ free base, i.p.) (B), and current-clamp recording was done at a resting potential of $-70 \mathrm{mV}$ in the presence of bath-applied picrotoxin to block $G_{A B A_{A}}$ receptors. C, Summary of results demonstrates that the EPSP paired-pulse ratio (P2/P1; ordinate) is significantly decreased $10 \mathrm{~min}$ or 1 or $24 \mathrm{~h}$ after systemic injection of nicotine (solid bars) relative to saline-treated controls (open bars; $p$ values are shown for each pair). Absolute $\mathrm{P} 1$ or $\mathrm{P} 2$ amplitudes were measured from the same baseline, which is indicated by the horizontal dashed line in $\boldsymbol{A}$ or $\boldsymbol{B}$, but the nicotine treatment-induced reduction in PPR is evident even if calculating $\mathrm{P} 2$ amplitudes from the tail of the $\mathrm{P} 1$ response at the time of the second pulse. These results suggest that nicotine exposure increases the probability of presynaptic glutamate release.

In support this notion, experiments using nAChR $\alpha 7$ or $\beta 2$ subunit $\mathrm{KO}$ mice still showed nicotine-induced increases in the AMPA/NMDA ratios, further supporting $\mathrm{nAChR}$ redundancy in the effect.

\section{Interpretation of findings regarding systemic nicotine-induced effects}

How do $\alpha 7$ - or $\beta 2^{\star}$-nAChRs mediate systemic nicotine-induced increases in the AMPA/NMDA ratios? In the VTA, $\alpha 7-\mathrm{nAChRs}$ are thought to be principally expressed on glutamatergic terminals, and systemic injection of nicotine could activate these presynaptic $\alpha 7$-nAChRs to increase glutamatergic release onto VTA DA neurons (Mansvelder and McGehee, 2000; Mansvelder et al., 2002). Our experiments showed that the evEPSP PPR is significantly decreased $10 \mathrm{~min}$ or 1 or $24 \mathrm{~h}$ after a single, systemic injection of nicotine, suggesting an increased probability of glutamate release onto DA neurons in nicotine-treated animals. Importantly, the nicotine-induced reduction of evEPSP PPR occurs earlier than the nicotine-induced increase in the AMPA/NMDA ratios (seen first at $10 \mathrm{~min}$ or $1 \mathrm{~h}$, respectively), indicating a temporal relationship that also could be causal-that the nicotine-induced presynaptic effects may play a role in triggering the increase of the AMPA/NMDA ratios. However, interpreta-
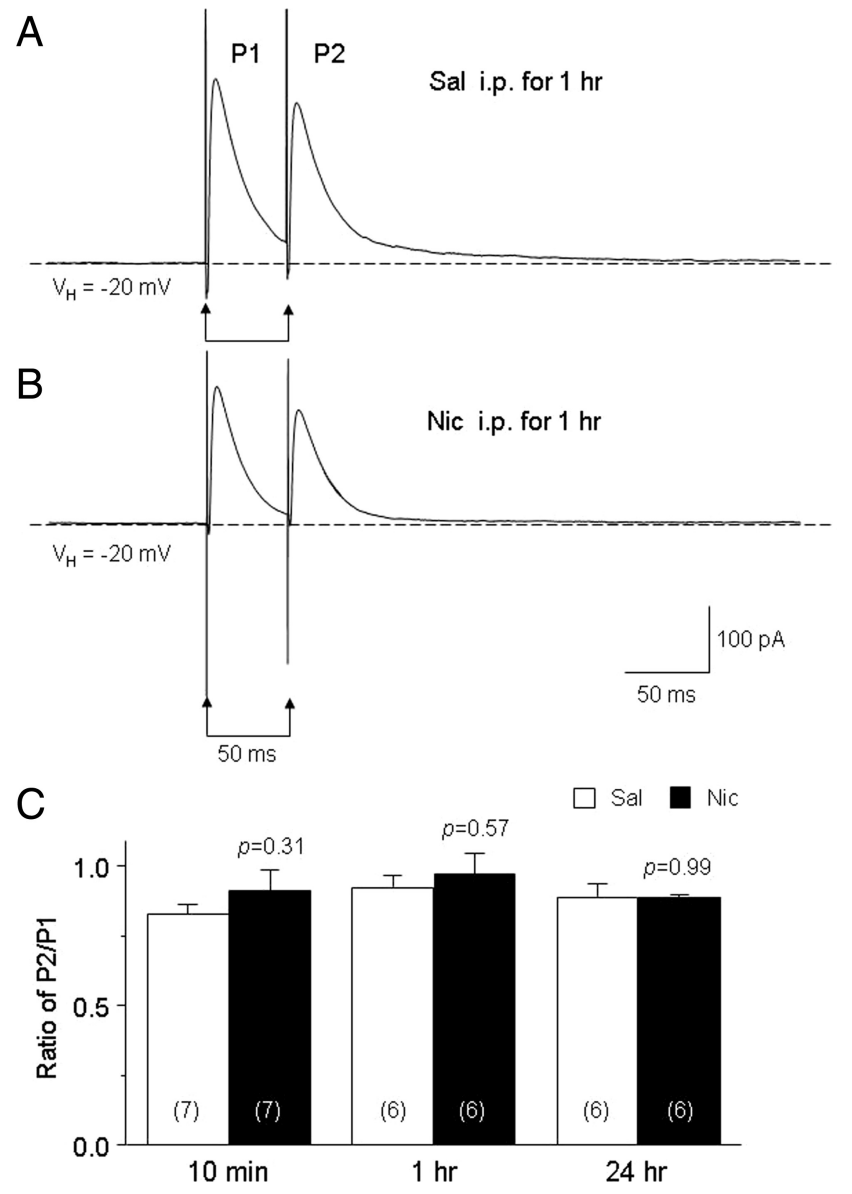

Figure 8. Effects of systemic nicotine exposure on IPSCS. A, B, Representative traces are shown for paired-pulse stimulation at an interpulse interval of $50 \mathrm{~ms}$ of IPSCs on DA neurons in rat VTA slices. Slices were prepared $1 \mathrm{~h}$ after animals were given a single injection of saline (Sal) (A) or nicotine (Nic) $(0.17 \mathrm{mg} / \mathrm{kg}$ free base, i.p.) (B), and voltage-clamp recoding was done at a holding potential of $-20 \mathrm{mV}$ in the presence of bath-applied NBQX (10 $\mu \mathrm{m})$ and D-APV (50 $\mu \mathrm{m})$ to block glutamatergic responses. C, Summary of results demonstrates that the IPSC paired pulse ratio (P2/P1) is not significantly altered ( $p$ values are shown for each pair) 10 min or 1 or $24 \mathrm{~h}$ after systemic injection of nicotine (solid bars) relative to saline-treated controls (open bars). Absolute $\mathrm{P} 1$ or $\mathrm{P} 2$ amplitudes were measured from the same baseline, which is indicated by the horizontal dashed line in $\boldsymbol{A}$ or $\boldsymbol{B}$, but equivalent results are obtained even if calculating $\mathrm{P} 2$ amplitudes from the tail of the $P 1$ response These results suggest that nicotine exposure has no effect on the probability of presynaptic GABA release.

tion of PPR studies alone can be complicated, in part because these studies rely upon empirically derived stimulus conditions, alteration of which could affect outcomes, and so we also assessed features of mEPSCs and mIPSCs in neurons from nicotine- or saline-treated animals. The latter studies did not indicate an increase in mEPSC frequency, just an increase in mEPSC amplitude. Nevertheless, it is not uncommon for there to be mismatches in results from PPR and mEPSC studies. For example, systemic cocaine treatment increases mEPSC frequency and amplitude but does not significantly alter evEPSC PPR assessed in VTA DA neurons (Thomas et al., 2001; Ungless et al., 2001). Chronic treatment of rats with ethanol also increases mEPSC frequency and amplitude but does not affect evEPSC PPR (Stuber et al., 2008). It is possible that results from PPR and mESPC studies do not always agree because neurotransmitter release contributing to mEPSCs or mIPSCs can have $\mathrm{Ca}^{2+}$-dependent and $\mathrm{Ca}^{2+}$-independent components, and PPR results can reflect contributions from action potential- and $\mathrm{Ca}^{2+}$-dependent neu- 


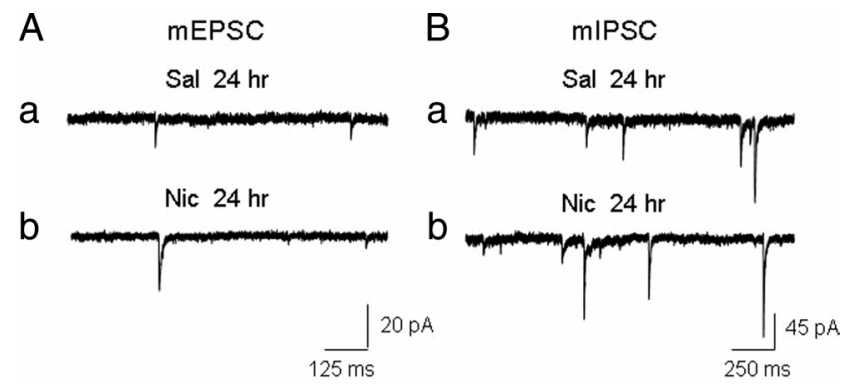

C mEPSC

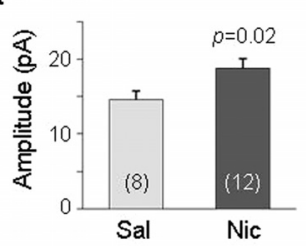

D mIPSC

a

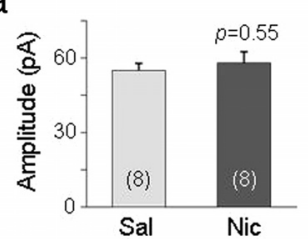

b

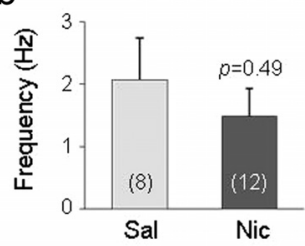

b

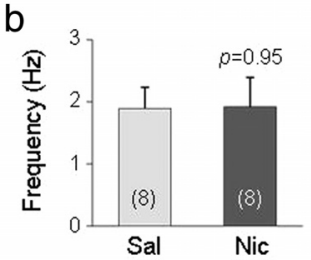

Figure 9. A single injection of nicotine significantly increases $m E P S C$ amplitude. $\boldsymbol{A}, \boldsymbol{B}$, Typical traces of mEPSCs $(\boldsymbol{A})$ or mIPSCs $(\boldsymbol{B})$ recorded $24 \mathrm{~h}$ after a single injection of saline (Sal) $(\boldsymbol{A a})$ or nicotine (Nic) $0.17 \mathrm{mg} / \mathrm{kg}$, i.p.) (Bb). C, D, Summary of results shows that, relative to normal saline controls (lightly shaded bars), systemic injection of nicotine significantly increases mEPSC amplitude (Ca, darkly shaded bar) but not mEPSC frequency $(\boldsymbol{C} \boldsymbol{b})$, mIPSC amplitude (Da), or mIPSC frequency $(\boldsymbol{D} \boldsymbol{b})$.

rotransmitter release (Maeda et al., 2009). Given these considerations and caveats, we favor the interpretation that systemic exposure to nicotine increases glutamatergic synaptic plasticity via time-dependent effects on both presynaptic and postsynaptic mechanisms.

VTA DA neurons also receive GABAergic inputs from local interneurons and projection fibers from the NAc and ventral pallidum (Walaas and Fonnum, 1980; Kalivas et al., 1993; Steffensen et al., 1998). Evidence has indicated that DA neurons are under tonic inhibitory control by GABA, and that the removal of this inhibition by infusion of $\mathrm{GABA}_{\mathrm{A}}$ antagonists into the VTA leads to an increase of DA release in the NAc and behavioral reinforcement (Westerink et al., 1996; David et al., 1997; Ikemoto et al., 1997a,b). Previous studies in VTA slices showed that perfusion with nicotine for $10 \mathrm{~min}$ significantly decreased the amplitude of evoked IPSCs, and $\beta 2^{*}$-nAChRs were substantially desensitized by this treatment so that a nicotinic agonist no longer depolarized GABAergic neurons sufficiently enough to fire action potentials (Mansvelder et al., 2002). These results suggest that nicotine quickly desensitizes $\beta 2^{\star}$-nAChRs on GABAergic neurons (within $10 \mathrm{~min}$ ) and results in a disinhibition of DA neuronal firing (Mansvelder et al., 2002). However, our findings indicate that systemic nicotine exposure does not produce changes, relative to saline-treatment controls, in GABAergic transmission $10 \mathrm{~min}$ or 1 or $24 \mathrm{~h}$ afterward. Because effects on GABA transmission might fade upon more prolonged exposure to nicotine, further investigation using finer temporal resolution seems warranted.

A

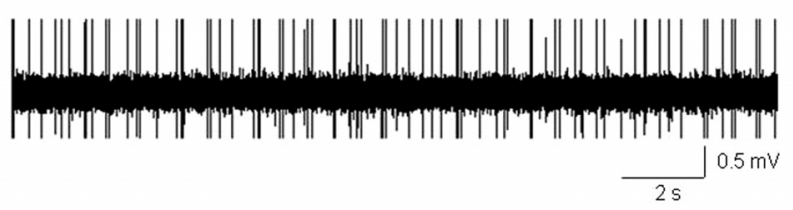

B
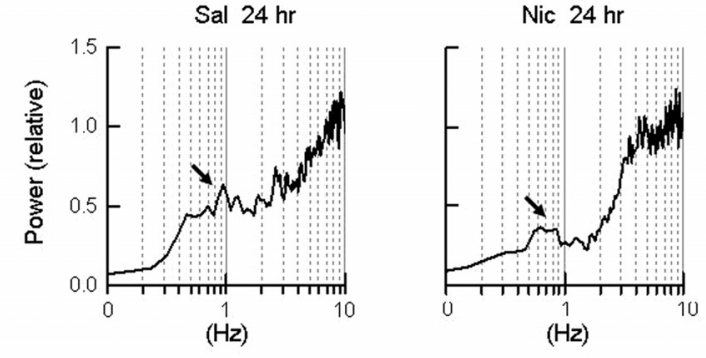

C

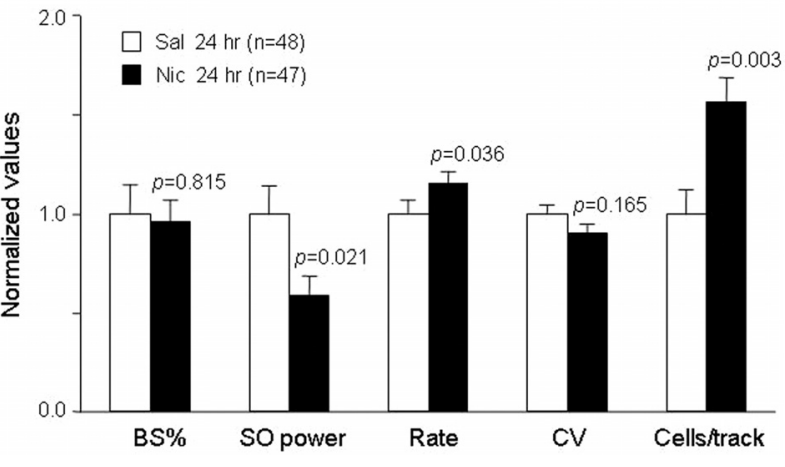

Figure 10. Effects of systemic nicotine exposure on firing activity in VTA DA neurons. $\boldsymbol{A}, \mathrm{A}$ typical trace for an extracellular, single unit recording from a VTA DA neuron in an anesthetized rat. $B$, Comparison of slow oscillations $(0.5-1.5 \mathrm{~Hz})$ in rat DA neuronal firing measured $24 \mathrm{~h}$ after injections with nicotine (Nic) $(0.17 \mathrm{mg} / \mathrm{kg}$ free base, i.p.) or saline (Sal). C, A summary of findings showing features of VTA DA neuronal firing properties $24 \mathrm{~h}$ after animals were injected with saline (open bars) or nicotine (solid bars). The $p$ values are for differences relative to salinetreated controls. Results show that a single nicotine exposure significantly decreases the power of slow oscillations $\left(P_{0.5-1.5 \mathrm{~Hz}}\right)$ and increases the firing rate (Rate), but has no effect on either the number of spikes in bursts (BS\%) or the coefficient of variability of interspike intervals (CV). Nicotine exposure also shows a marked increase in the number of firing DA cells in each recording track (cells/track). These findings suggest that a single nicotine injection maintains a longlasting excitation of VTA DA neurons and switches silent to firing DA neurons.

\section{Mechanisms of the systemic nicotine-induced increase in the} AMPA/NMDA ratio

Mechanisms and pathways involved in the systemic nicotineinduced increase in glutamatergic synaptic strength are largely unknown. Our results demonstrate that systemic nicotine's effects on the AMPA/NMDA ratio are blocked by MK-801, which implies involvement of NMDA receptors and is consistent with previous findings implicating NMDA receptors in the cocaineinduced increase in the AMPA/NMDA ratio $24 \mathrm{~h}$ after drug treatment (Ungless et al., 2001; Saal et al., 2003). Evidence that local injection of NMDA receptor antagonists into the VTA abolishes systemic nicotine-induced increases in DA release in the NAc and behavioral sensitization (Schilström et al., 1998) is consistent with these ideas, as is the indication that nicotine exposure induces an increase in spermine-sensitive, presumably GluR1(nonGluR2)-AMPA receptor function. However, it has been reported that acute perfusion of cocaine on VTA slices increases NMDA receptor-mediated currents without altering AMPA receptor transmission (Schilström et al., 2006). These studies collectively suggest that addictive drugs may modulate NMDA and AMPA receptor function with different time courses, initially increasing 
NMDA and later increasing AMPA receptor expression/function (Malenka and Nicoll, 1999; Malenka and Bear, 2004). Systemic exposure to nicotine appears to induce similar dynamic alteration in NMDA and AMPA receptor-mediated currents (supplemental Fig. 2, available at www.jneurosci.org as supplemental material). These temporal dynamics coupled with the particulars of site and route of experimental drug delivery are likely to be very important toward an improved understanding of NMDA receptor-dependent upregulation of AMPA receptor expression/ function by addictive drugs. On the other hand, unlike effects of cocaine, which are blocked by dopamine receptor antagonists (Ungless et al., 2001), or the calcineurin signal transduction pathway blocker cyclosporine (Addy et al., 2007), nicotine's induction of glutamatergic synaptic plasticity is insensitive to block by these manipulations. This suggests that nAChRs are the critical and rather proximal targets mediating the nicotinic effect and work through pathways distinct from those involved in cocaine's effects. Based on these results, we propose that nicotine administration, acting in ways sometimes shared by addictive drugs, increases glutamate release onto DA neurons in the VTA, initially activates NMDA receptor-mediated signaling cascades, which in turn upregulates AMPA receptors, and induces glutamatergic synaptic plasticity.

\section{References}

Addy NA, Fornasiero EF, Stevens TR, Taylor JR, Picciotto MR (2007) Role of calcineurin in nicotine-mediated locomotor sensitization. J Neurosci 27:8571-8580.

Argilli E, Sibley DR, Malenka RC, England PM, Bonci A (2008) Mechanism and time course of cocaine-induced long-term potentiation in the ventral tegmental area. J Neurosci 28:9092-9100.

Benwell ME, Balfour DJ (1992) The effects of acute and repeated nicotine treatment on nucleus accumbens dopamine and locomotor activity. Br J Pharmacol 105:849-856.

Bissière S, Humeau Y, Lüthi A (2003) Dopamine gates LTP induction in lateral amygdala by suppressing feedforward inhibition. Nat Neurosci 6:587-592.

Bunney BS, Grace AA (1978) Acute and chronic haloperidol treatment: comparison of effects on nigral dopaminergic cell activity. Life Sci 23:1715-1727.

Bunney BS, Aghajanian GK, Roth RH (1973) Comparison of effects of L-dopa, amphetamine and apomorphine on firing rate of rat dopaminergic neurones. Nat New Biol 245:123-125.

Charpantier E, Barnéoud P, Moser P, Besnard F, Sgard F (1998) Nicotinic acetylcholine subunit mRNA expression in dopaminergic neurons of the rat substantia nigra and ventral tegmental area. Neuroreport 9:30973101.

Charpantier E, Besnard F, Graham D, Sgard F (1999) Diminution of nicotinic receptor alpha 3 subunit mRNA expression in aged rat brain. Brain Res Dev Brain Res 118:153-158.

Chiodo LA, Bunney BS (1983) Typical and atypical neuroleptics: differential effects of chronic administration on the activity of A9 and A10 midbrain dopaminergic neurons. J Neurosci 3:1607-1619.

Clarke PB (1991) Nicotinic receptor blockade therapy and smoking cessation. Br J Addict 86:501-505.

Corrigall WA, Coen KM (1989) Nicotine maintains robust self-administration in rats on a limited-access schedule. Psychopharmacology (Berl) 99:473-478.

Dani JA, Heinemann S (1996) Molecular and cellular aspects of nicotine abuse. Neuron 16:905-908.

David V, Durkin TP, Cazala P (1997) Self-administration of the GABAA antagonist bicuculline into the ventral tegmental area in mice: dependence on D2 dopaminergic mechanisms. Psychopharmacology (Berl) 130:85-90.

Gao M, Liu CL, Yang S, Jin GZ, Bunney BS, Shi WX (2007) Functional coupling between the prefrontal cortex and dopamine neurons in the ventral tegmental area. J Neurosci 27:5414-5421.

Grace AA, Bunney BS (1980) Nigral dopamine neurons: intracellular re- cording and identification with L-dopa injection and histofluorescence. Science 210:654-656.

Grace AA, Bunney BS (1983) Intracellular and extracellular electrophysiology of nigral dopaminergic neurons-1. Identification and characterization. Neuroscience 10:301-315.

Heikkinen AE, Möykkynen TP, Korpi ER (2009) Long-lasting modulation of glutamatergic transmission in VTA dopamine neurons after a single dose of benzodiazepine agonists. Neuropsychopharmacology 34:290-298.

Huang ZJ, Kirkwood A, Pizzorusso T, Porciatti V, Morales B, Bear MF, Maffei L, Tonegawa S (1999) BDNF regulates the maturation of inhibition and the critical period of plasticity in mouse visual cortex. Cell 98:739-755.

Ikemoto S, Murphy JM, McBride WJ (1997a) Self-infusion of GABA(A) antagonists directly into the ventral tegmental area and adjacent regions. Behav Neurosci 111:369-380.

Ikemoto S, Kohl RR, McBride WJ (1997b) GABA(A) receptor blockade in the anterior ventral tegmental area increases extracellular levels of dopamine in the nucleus accumbens of rats. J Neurochem 69:137-143.

Imperato A, Di Chiara G (1986) Preferential stimulation of dopamine release in the nucleus accumbens of freely moving rats by ethanol. J Pharmacol Exp Ther 239:219-228.

Johnson SW, North RA (1992) Opioids excite dopamine neurons by hyperpolarization of local interneurons. J Neurosci 12:483-488.

Kalivas PW, Churchill L, Klitenick MA (1993) GABA and enkephalin projection from the nucleus accumbens and ventral pallidum to the ventral tegmental area. Neuroscience 57:1047-1060.

Klink R, de Kerchove d'Exaerde A, Zoli M, Changeux JP (2001) Molecular and physiological diversity of nicotinic acetylcholine receptors in the midbrain dopaminergic nuclei. J Neurosci 21:1452-1463.

Le Novère N, Corringer PJ, Changeux JP (2002) The diversity of subunit composition in nAChRs: evolutionary origins, physiologic and pharmacologic consequences. J Neurobiol 53:447-456.

Liu QS, Pu L, Poo MM (2005) Repeated cocaine exposure in vivo facilitates LTP induction in midbrain dopamine neurons. Nature 437:1027-1031.

Maeda M, Tanaka E, Shoudai K, Nonaka K, Murayama N, Ito Y, Akaike N (2009) Differential effects of divalent cations on spontaneous and evoked glycine release from spinal interneurons. J Neurophysiol 101:1103-1113.

Malenka RC, Bear MF (2004) LTP and LTD: an embarrassment of riches. Neuron 44:5-21.

Malenka RC, Nicoll RA (1999) Long-term potentiation-a decade of progress? Science 285:1870-1874.

Mansvelder HD, McGehee DS (2000) Long-term potentiation of excitatory inputs to brain reward areas by nicotine. Neuron 27:349-357.

Mansvelder HD, Keath JR, McGehee DS (2002) Synaptic mechanisms underlie nicotine-induced excitability of brain reward areas. Neuron 33:905-919.

Margolis EB, Hjelmstad GO, Bonci A, Fields HL (2003) Kappa-opioid agonists directly inhibit midbrain dopaminergic neurons. J Neurosci 23:9981-9986.

Meredith RM, Floyer-Lea AM, Paulsen O (2003) Maturation of long-term potentiation induction rules in rodent hippocampus: role of GABAergic inhibition. J Neurosci 23:11142-11146.

Nashmi R, Xiao C, Deshpande P, McKinney S, Grady SR, Whiteaker P, Huang Q, McClure-Begley T, Lindstrom JM, Labarca C, Collins AC, Marks MJ, Lester HA (2007) Chronic nicotine cell specifically upregulates functional alpha $4^{*}$ nicotinic receptors: basis for both tolerance in midbrain and enhanced long-term potentiation in perforant path. J Neurosci 27:8202-8218.

Nestler EJ (1992) Molecular mechanisms of drug addiction. J Neurosci 12:2439-2450.

Pu L, Liu QS, Poo MM (2006) BDNF-dependent synaptic sensitization in midbrain dopamine neurons after cocaine withdrawal. Nat Neurosci 9:605-607.

Saal D, Dong Y, Bonci A, Malenka RC (2003) Drugs of abuse and stress trigger a common synaptic adaptation in dopamine neurons. Neuron 37:577-582.

Sargent PB (1993) The diversity of neuronal nicotinic acetylcholine receptors. Annu Rev Neurosci 16:403-443.

Schilström B, Svensson HM, Svensson TH, Nomikos GG (1998) Nicotine and food induced dopamine release in the nucleus accumbens of the rat: putative role of alpha7 nicotinic receptors in the ventral tegmental area. Neuroscience 85:1005-1009. 
Schilström B, Yaka R, Argilli E, Suvarna N, Schumann J, Chen BT, Carman M, Singh V, Mailliard WS, Ron D, Bonci A (2006) Cocaine enhances NMDA receptor-mediated currents in ventral tegmental area cells via dopamine D5 receptor-dependent redistribution of NMDA receptors. J Neurosci 26:8549-8558.

Shi WX, Pun CL, Zhang XX, Jones MD, Bunney BS (2000) Dual effects of D-amphetamine on dopamine neurons mediated by dopamine and nondopamine receptors. J Neurosci 20:3504-3511.

Shi WX, Zhang XY, Pun CL, Bunney BS (2007) Clozapine blocks D-amphetamine-induced excitation of dopamine neurons in the ventral tegmental area. Neuropsychopharmacology 32:1922-1928.

Steffensen SC, Svingos AL, Pickel VM, Henriksen SJ (1998) Electrophysiological characterization of GABAergic neurons in the ventral tegmental area. J Neurosci 18:8003-8015.

Stolerman IP, Shoaib M (1991) The neurobiology of tobacco addiction. Trends Pharmacol Sci 12:467-473.

Stuber GD, Hopf FW, Hahn J, Cho SL, Guillory A, Bonci A (2008) Voluntary ethanol intake enhances excitatory synaptic strength in the ventral tegmental area. Alcohol Clin Exp Res 32:1714-1720.

Thomas MJ, Beurrier C, Bonci A, Malenka RC (2001) Long-term depression in the nucleus accumbens: a neural correlate of behavioral sensitization to cocaine. Nat Neurosci 4:1217-1223.

Ungless MA, Whistler JL, Malenka RC, Bonci A (2001) Single cocaine exposure in vivo induces long-term potentiation in dopamine neurons. Nature 411:583-587.

Ungless MA, Magill PJ, Bolam JP (2004) Uniform inhibition of dopamine neurons in the ventral tegmental area by aversive stimuli. Science 303:2040-2042.

Vezina P, McGehee DS, Green WN (2007) Exposure to nicotine and sensitization of nicotine-induced behaviors. Prog Neuropsychopharmacol Biol Psychiatry 31:1625-1638.

Walaas I, Fonnum F (1980) Biochemical evidence for gamma-amino- butyrate containing fibres from the nucleus accumbens to the substantia nigra and ventral tegmental area in the rat. Neuroscience 5:63-72.

Walters CL, Brown S, Changeux JP, Martin B, Damaj MI (2006) The beta2 but not alpha7 subunit of the nicotinic acetylcholine receptor is required for nicotine-conditioned place preference in mice. Psychopharmacology (Berl) 184:339-344.

Westerink BH, Kwint HF, deVries JB (1996) The pharmacology of mesolimbic dopamine neurons: a dual-probe microdialysis study in the ventral tegmental area and nucleus accumbens of the rat brain. J Neurosci 16:2605-2611.

Wigström H, Gustafsson B (1983) Facilitated induction of hippocampal long-lasting potentiation during blockade of inhibition. Nature 301:603-604.

Yang K, Hu J, Lucero L, Liu Q, Zheng C, Zhen X, Jin G, Lukas RJ, Wu J (2009) Distinctive nicotinic acetylcholine receptor functional phenotypes of rat ventral tegmental area dopaminergic neurons. J Physiol 587:345-361.

Ye JH, Zhang J, Xiao C, Kong JQ (2006) Patch-clamp studies in the CNS illustrate a simple new method for obtaining viable neurons in rat brain slices: glycerol replacement of $\mathrm{NaCl}$ protects CNS neurons. J Neurosci Methods 158:251-259.

Zanetti L, de Kerchove D'Exaerde A, Zanardi A, Changeux JP, Picciotto MR Zoli M (2006) Inhibition of both alpha7 ${ }^{*}$ and beta2 ${ }^{*}$ nicotinic acetylcholine receptors is necessary to prevent development of sensitization to cocaine-elicited increases in extracellular dopamine levels in the ventral striatum. Psychopharmacology (Berl) 187:181-188.

Zanetti L, Picciotto MR, Zoli M (2007) Differential effects of nicotinic antagonists perfused into the nucleus accumbens or the ventral tegmental area on cocaine-induced dopamine release in the nucleus accumbens of mice. Psychopharmacology (Berl) 190:189-199.

Zhang D, Yang S, Jin GZ, Bunney BS, Shi WX (2008) Oscillatory firing of dopamine neurons: differences between cells in the substantia nigra and ventral tegmental area. Synapse 62:169-175. 